\title{
Neue Identitäten - neue Genealogien: Jacques-Louis Davids künstlerische Selbstdarstellung nach dem 9. Thermidor $1794^{*}$
}

Kunst und Politik stehen bei kaum einem Künstler in einem so engen Interdependenzverhältnis wie bei Jacques-Louis David in der Zeit der Französischen Revolution. ${ }^{1}$ Ab 1791 wird der Maler zu einem Parteigänger des sich dann in der Terreur radikalisierenden revolutionären Systems und widmet sich zunehmend der Politik: Bereits 1790 war David in die Société des amis de la Constitution (die Vorläuferinstitution des Jakobinerclubs) eingetreten. Er steht seit diesem Jahr der Commune des arts vor und setzt sich in der Assemblée nationale für die Abschaffung sämtlicher Akademien ein. 1791 unterschreibt er die Petition zur Absetzung Ludwigs XVI., am 4. April 1792 organisiert er sein erstes Revolutionsfest zu Ehren des Schweizerregiments von Chateauvieux. Am 17. September 1792 wird er als Abgeordneter des Département Paris in den Nationalkonvent gewählt, am 13. Oktober ins Comité d'instruction publique berufen, wo er als offizieller Organisator der Revolutionsfeste fungiert und die Kunstpolitik der Revolutionszeit maßgeblich bestimmt. ${ }^{2}$

In den verschiedenen von der Revolution hervorgebrachten Kunst-Kommissionen und -Vereinigungen spielt er eine führende Rolle, so in der neugeschaffenen Commission temporaire des Arts, die Anfang 1794 die Commission des monuments ersetzt, und in der Section du muséum. In der Abstimmung vom 16. - 19. Januar 1793 spricht er sich für die Exekution Ludwigs XVI. aus, woraufhin sich seine Gattin, Charlotte Pécoul, eine überzeugte Royalistin, im März 1794 von ihm scheiden lässt. Als flammender Parteigänger Maximilien de Robespierres wird er im Juni 1793 zum Präsidenten des radikalrepu- blikanischen Jakobinerclubs gewählt und am 14. September 1793 Mitglied des Comité de sîreté générale, ${ }^{3}$ in dem er zum Vorsitzenden der dortigen Section des interrogatoires aufsteigt. $\mathrm{Ab}$ dem 5. Januar 1794 schließlich amtiert er kurzzeitig als Präsident des Nationalkonvents. Jetzt arbeitet er der Terreur aktiv zu.

Im Folgenden wird zu untersuchen sein, ob sich Davids Selbststilisierungen nach dem Scheitern dieses radikalen Systems so kategorial veränderten wie die politische Kultur Frankreichs nach der Französischen Revolution und welcher Strategien der künstlerischen Selbstdarstellung und Selbstlegitimierung er sich nach dem 9. Thermidor 1794 und dem vorausgegangenen `Vatermord ‘ am französischen König bediente. Hierzu werden schriftliche Selbstzeugnisse ebenso herangezogen wie das berühmte, in der Haft entstandene Selbstporträt von 1794. Davids Stilisierung zum autonomen, vaterlosen Künstler wird anhand seiner autobiographischen Textproduktion nachvollzogen. Kompensatorisch zum Vaterverlust schuf er sich eine neue Genealogie, in der er selbst die Vaterrolle eines père de l'école davidienne einnahm und sich ganz über seine `Söhne in aestheticis, seine Schüler, definierte, wie man schon am Sokrates von 1787 ablesen kann. Davids ästhetisches Konzept in der Zeit vor der Revolution wird anhand der Horatier (1784) und des Brutus (1789) skizziert, ein republikanisches Idealkonzept, das David dann wesentlich später im Léonidas (1799-1814) wieder aufgriff, um - so die These - das Scheitern eines unfanatisierten Republikanismus im Kontext des napoleonischen Imperialismus darzustellen. 


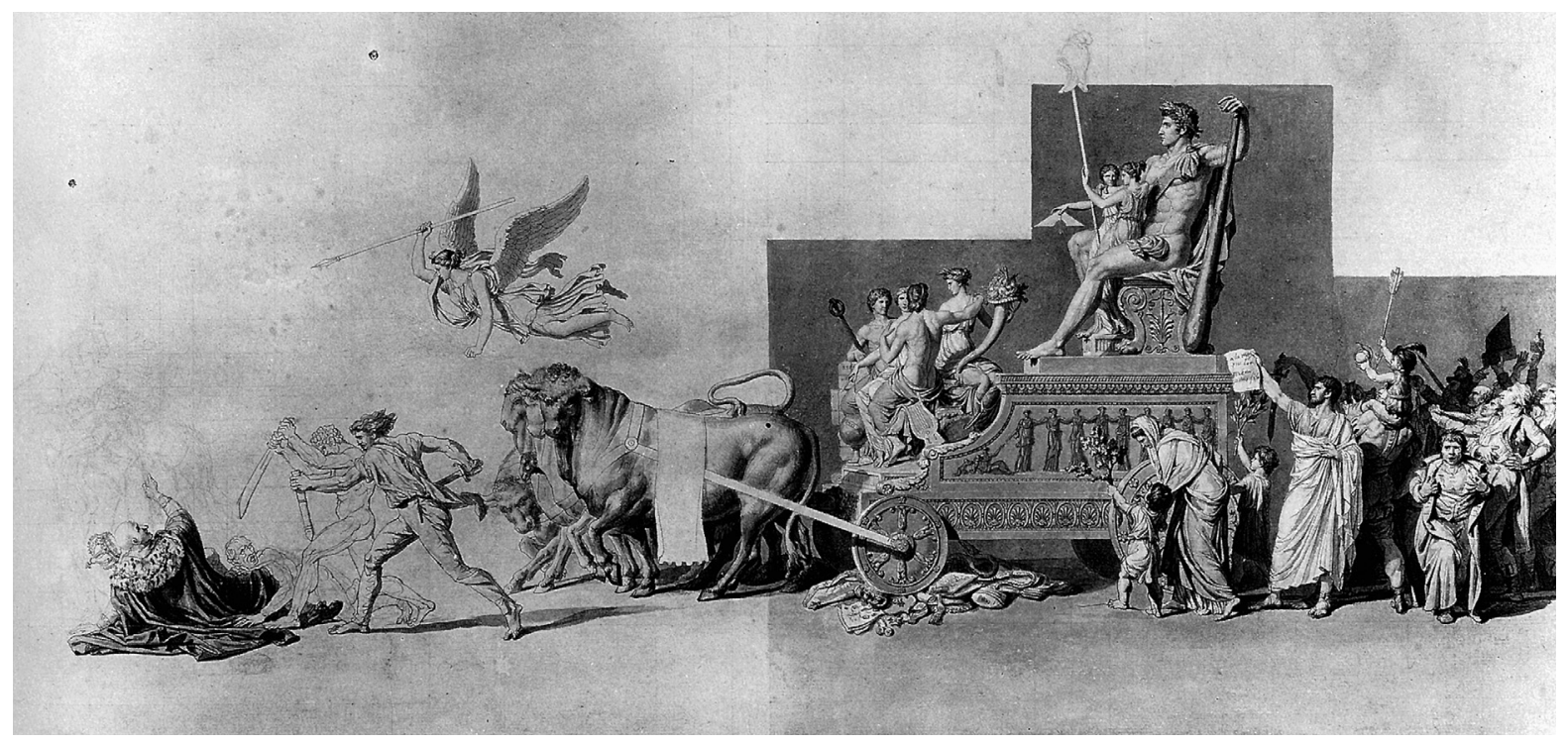

1 Jacques-Louis David, Le Triomphe du Peuple français, 1794, Bleimine, laviert, 38,6 $671 \mathrm{~cm}$. Paris, Musée Carnavalet

\section{Den republikanischen Volkskörper stählen und einschwören}

Davids Kunstproduktion musste zwischen 1792 und 1794 hinter seinem politischen Engagement zurückstehen. Sie verlagerte sich zunehmend auf ephemere Gattungen wie Festdekorationen oder auf Projekte für Denkmäler im öffentlichen Raum (z. B. für eine $50 \mathrm{~m}$ hohe Monumentalstatue des peuple, die sich auf den Trümmern der Königsgalerie von Notre-Dame erheben sollte und in etwas weniger kolossaler Form beim Fest des Höchsten Wesens am 8. Juni 1794 für kurze Zeit neben der temporären montagne zu stehen kam). An ausgeführten Gemälden finden sich in dieser bewegten Zeit nur drei Bilder, in denen der Maler den sogenannten Revolutionsmärtyrern als seinen ermordeten `Brüdern ein Erinnerungsmal setzte: ${ }^{4}$ Anfang 1793 LouisMichel Le Peletier de Saint-Fargeau, der wegen seines Votums für die Hinrichtung des französischen Monarchen von einem Mitglied der königlichen Leibgarde ermordet worden war; dann dem am 13. Juli 1793 von der Royalistin Charlotte Corday in seiner Badewanne erstochenen Ultrarevolutionär Jean-Paul Marat; schließlich dem zum Märtyrer verklärten 13-jährigen Pferdeknecht Joseph Barra, der 1793 bei Kämpfen in der Vendée einem Brigantenüberfall zum Opfer gefallen war. Der in Davids Darstellung geschlechtsambigue Kindermärtyrer sollte zum vorbildlichen Bruder der Jugend Frankreichs stilisiert werden.

Auch auf Davids Entwurf für den Bühnenvorhang der Opéra vom Frühjahr $1794^{5}$ (Abb. 1) sieht man hinter dem Triumphwagen des französischen Volkes erneut eine Gruppe von Revolutionsmärtyrern mit ihren anklagend hochgehaltenen `Heiligenattributen $\triangleleft$ der Klinge der Guillotine, der Giftphiole und den Gefängnisketten. In der ersten Reihe entblößt Marat ostentativ seine von Skrofeln entstellte Brust. Diese »allégorie de la Terreur « ${ }^{6}$ vereint zeitgenössische Königsmörder und historische Tugendhelden in einem zeitenüberbrückenden und allein von der Suggestion des Heroismus zusammengehaltenen Triumphzug - der régicide selbst ist links in höchster Drastik dargestellt. ${ }^{7}$

Als Zeremonienmeister der Festzüge der Revolutionszeit brachte David in diesen republikanischen Inszenierungen einer neuen, autonomen und egalitär-brüderlichen Vergemeinschaftung 


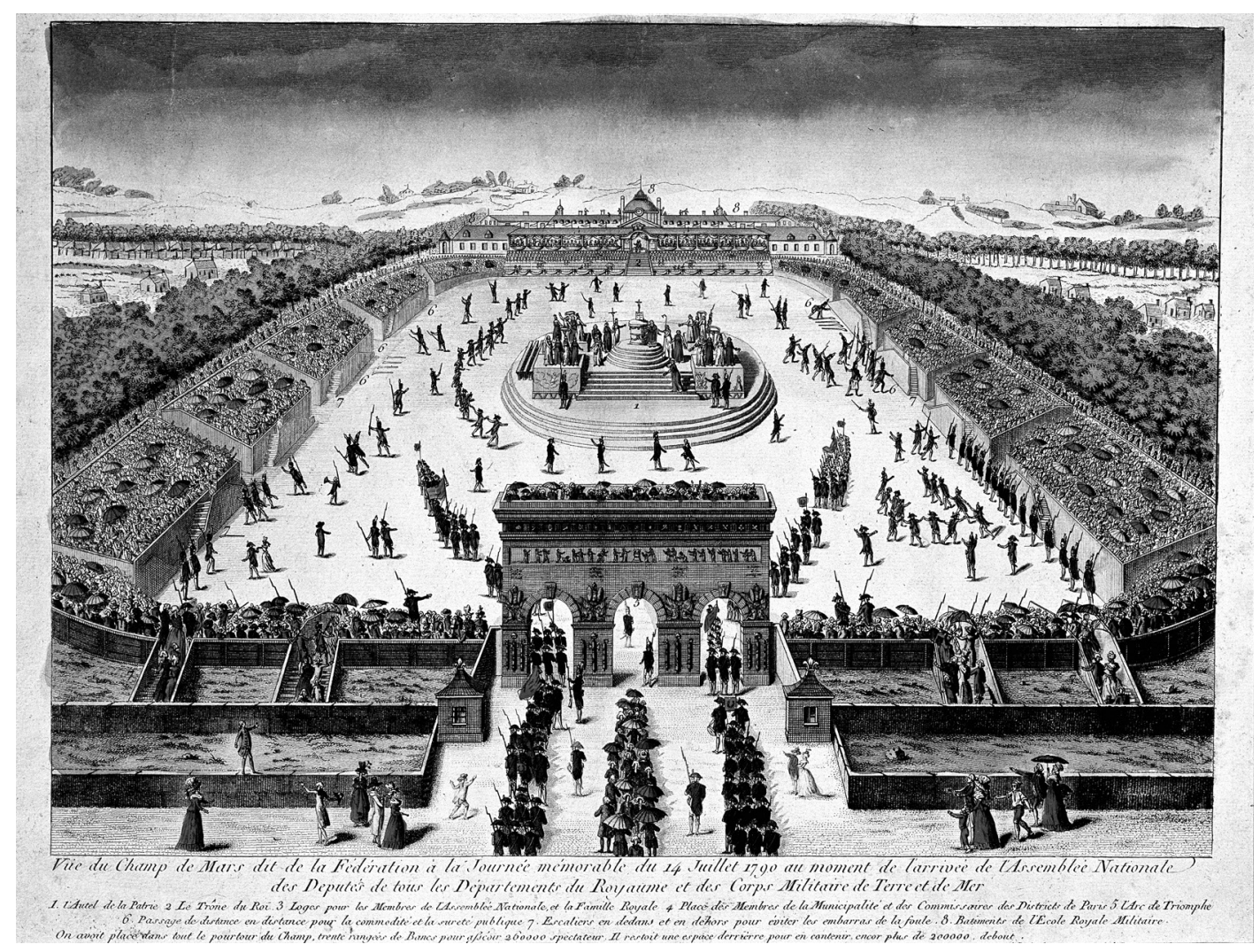

2 Anonym, Fête de la Fédération sur le champ de Mars à Paris, le 14 juillet 1790, l'arrivée des Fédérés, 1790, kolorierter Stich, $35 \times 45 \mathrm{~cm}$. Versailles, Châteaux de Versailles et de Trianon

jenseits der monarchisch-patriarchalischen Ordnung ästhetische Prinzipien zum Einsatz, die weite Teile seines malerischen Euvres prägen. Diese Festzüge folgten einer bis ins letzte Detail durchgeplanten Choreographie: Die hier erstmals öffentlich auftretenden Menschenmassen wurden einerseits einer körperlichen Konditionierung ihrer Bewegungsabläufe, ${ }^{8}$ andererseits einer strikten Unterteilung nach Alter, Geschlecht, Wohnort und Berufsgruppe unterworfen, um sie in Untereinheiten unterscheidbar und manövrierbar, damit auch manipulierbar zu machen. Eine Hauptfunktion dieser Zeremonien, deren Meister David ab 1792 war, bestand darin, Plätze nationaler Identifikation, Orte der Konstitution einer republikanischen Gemeinschaft zu schaffen. Es sollten jedermann zugängliche öffentliche Kommunikationsräume entstehen, in denen patriotische Gefühlsbildung am neuen nachrevolutionären Menschen, dem homme régénéré, vorgenommen werden konnte. ${ }^{9}$

Das neue Ideal der fraternité, der Gemeinschaft der gleichgeordneten Brüder, fand in der Abschlussmanifestation der erstmals am 14. Juli 1790 mit größtem personellen und inszenatorischen Aufwand ausgerichteten Fête de la Fédération ihren sinnfälligen Ausdruck. Als Jahrestag des Sturms auf die Bastille markierte dieses Fest die Stunde Null, von der an neue, ewig gültige Erinnerungen geschaffen werden sollten; die spoetische Idee $<$ war hierbei die Zusammenführung und Zentrierung aller Franzosen in einem einigenden Akt auf dem Champ de Mars. Höhepunkt der Inszenierung war der eigentliche Akt der fédération mit dem Schwur des Generals der Nationalgarde, Lafayette, am Altar des Vaterlandes. Dieser Festakt der militärischen Vereinigung wandelte sich zu einer de- 


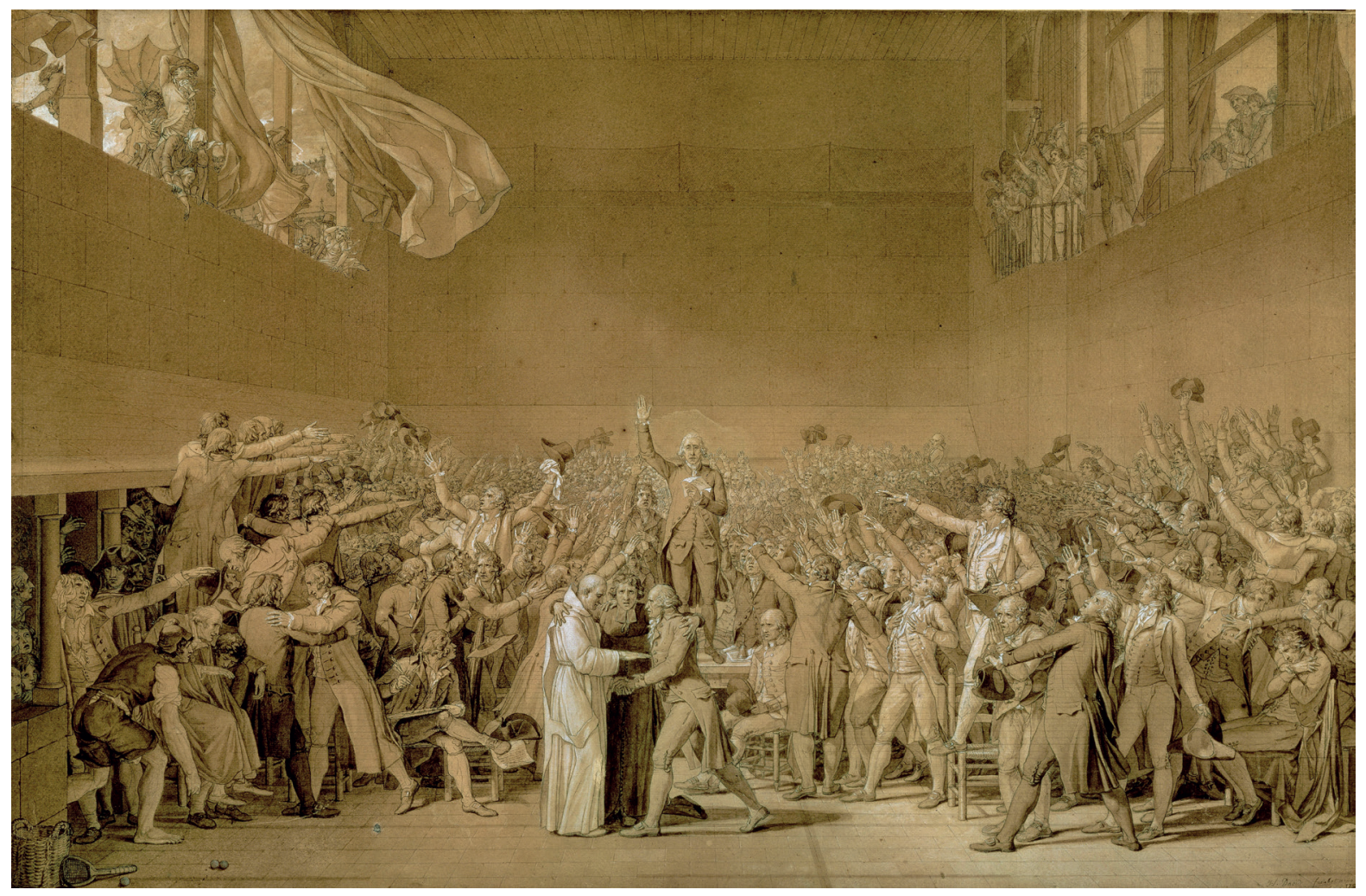

3 Jacques-Louis David, Le Serment du Jeu de Paume à Versailles le 20 juin 1789, 1791, Feder, Tinte, laviert, $66 \times 101$, 2 cm. Versailles, Châteaux de Versailles et de Trianon

monstrativen Unierung der gesamten Nation. Die ritualisierte Handlung - eine gemeinschaftliche Wiederholung des Bürgereids - sollte die Volksmassen für alle Zukunft auf die neuen revolutionären Ideale einschwören, sie zu einer Glaubensgemeinschaft vereinigen und zugleich den Gesellschaftsvertrag alljährlich erneuern. Das Volk erfuhr sich demnach als konstitutiven Teil des neuen Staatskörpers und feierte sich in der neu errichteten nationalen Arena selbst als Nation. Die Teilnehmer des Festes waren Teil der ästhetischen Selbstdarstellung der neuen politischen Verfassung, indem sie als Individuen zur Gestaltung des Ornaments der Masse beitrugen (Abb. 2). Zugleich aber war jeder einzelne Teilnehmer auch Betrachter dieses neuartigen Kunstwerks und insofern $\mathrm{Zu}$ schauer bei dieser theatralischen Inszenierung von Politik. Im simultanen Akt des Betrachtens und Partizipierens sollte er sich selbst als unentbehrlichen, allen anderen gleichgeordneten Teil der neuen republikanischen Ordnung erkennen. Tatsächlich zeichnete sich die Revolutionszeit durch ständig wiederholte Akte des Schwörens und Einschwörens einer noch krisenanfälligen jungen Republik auf ihre neuen Ideale aus. Der Schwur als eine gemeinschaftsstiftende Handlung reiner Gegenwärtigkeit mit Verpflichtungscharakter für die Zukunft ist am besten als Masseninszenierung handhabbar, weil er so von möglichst vielen Mitbürgern bezeugt und später einforderbar wird. In der krisenhaften Frühphase der Republik stellt er ein Ritual vor jeder Verschriftung von Gesetzen und Bürgerpflichten dar und garantiert damit das politische Funktionieren des neuen Staatsverbandes schon vor der Verfassungsgebung, die erst die neuen politischen Institutionen ab- 
sichert und ihr Funktionieren standardisiert. In der Anfangsphase der Revolution hat David ein einziges großes Historienbild in Angriff genommen, das eine solche Schwurszene darstellen sollte. Sein berühmter Serment du Jeu de Paume (Abb. 3) ist zugleich das erste Gemälde, das ein zeitgenössisches, tagespolitisches Massenereignis in monumentalem Format für darstellungswürdig befand. ${ }^{10}$ Gezeigt sind hier rund 600 Personen, die nur in der vorderen, reliefartig gegebenen Handlungszone durch Porträts individualisiert sind (z. B. spätere engagierte Jakobiner wie Robespierre, der Abbé Grégoire oder der Abbé Sieyès als Theoretiker des Dritten Standes). Dahinter jedoch geht die Darstellung in eine im Akt des Schwörens homogenisierte Menschenmasse über. Die dargestellte Handlung enthält daher gegensätzliche Elemente: Einerseits ist die Gemeinschaft im Augenblick des Schwurs stillgestellt, so vor allem im Zentrum des Geschehens um den Bürgermeister von Paris und Präsidenten der Assemblée nationale, Jean Sylvain Bailly. Andererseits findet man an den Rändern Momente von enthusiastischem Aktionismus: Hier werden flammende Reden gehalten, unter anderen von Mirabeau und Antoine Barnave als den wichtigsten Rhetoren der Revolution, wobei Redegestus und Schwurgestus kaum zu unterscheiden sind.

Der Inhalt des Eides vom 20. Juni 1789 beschwor die Konstitution eines neuen Gesellschaftsvertrages. Sein Kernpassus lautete: »de ne jamais se séparer, et de se rassembler partout où les circonstances l'exigeront, jusqu'à ce que la Constitution du royaume soit établie et affermie sur des fondements solides«. Es ging also um das Aufgeben von Individualität zugunsten einer untrennbar unierten Gemeinschaft, die dem Ideal eines geschlossenen Gesellschaftskörpers entsprach. In seiner ganz und gar nicht realistischen Darstellung einer politischen Idee bricht David die Einheit von Zeit und Ort - die aristotelische unité - zugunsten der Darstellung einer choreographisch umgesetzten unité de doctrine

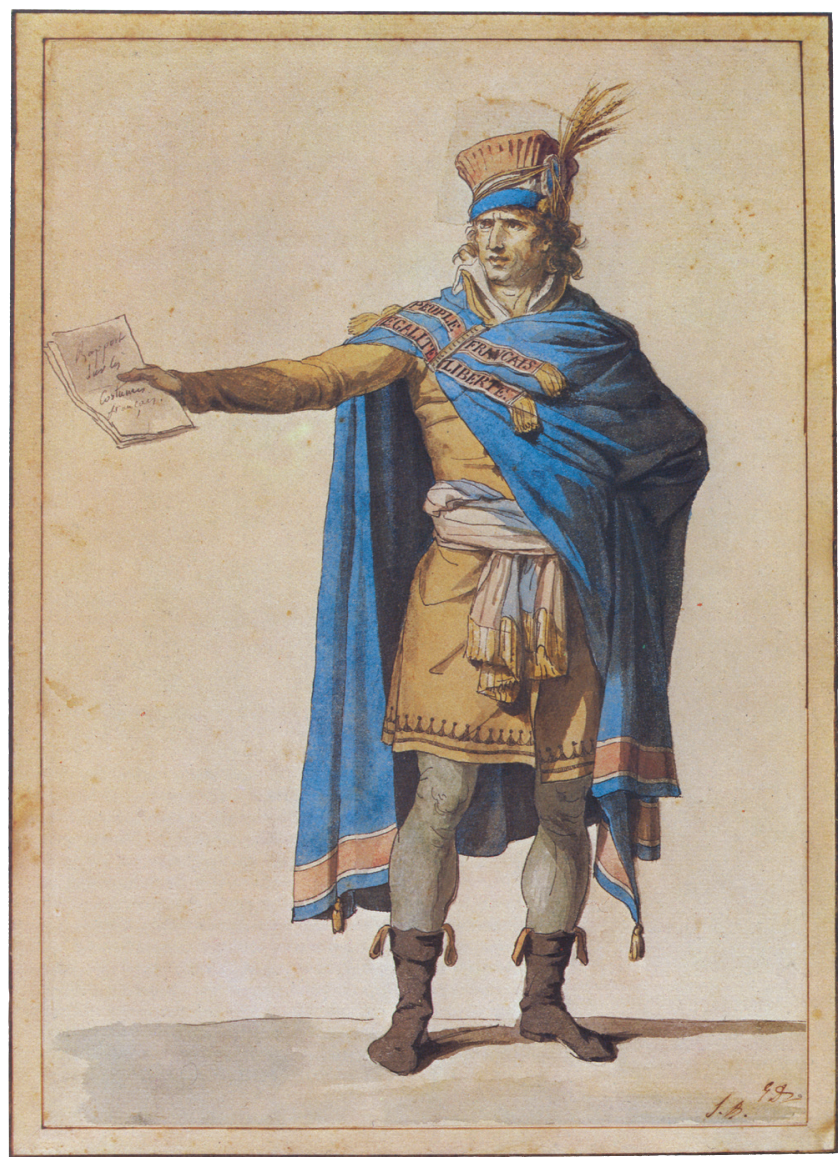

4 Jacques-Louis David, Le Représentant du peuple en fonction, 1794, Feder, Tinte und Aquarell, $35 \times 24 \mathrm{~cm}$. Paris, Musée Carnavalet

auf. Er zeigt die motorische Konditionierung der Körper, die nach Robespierre in eine totale Gleichschaltung der täglichen Bewegungen und Zeitabläufe münden sollte. Die Körper ordnen sich einer Idee der Einheit unter, die sich in immer gleicher formaler Gestaltung manifestiert: Diese Vorstellung einer Verschmelzung im einigenden Akt eines patriotisch-republikanischen Schwurs hat hier ihre künstlerische Umsetzung gefunden. In formaler Hinsicht folgt aus der verordneten unité reglementierte Gleichförmigkeit, uniformité, wie man sie in den von David entworfenen und von Vivant Denon gestochenen Uniformen für die Bürger, Volksvertreter und Verwaltungsbeamten der neuen Republik von 1794 findet (Abb. 4). 


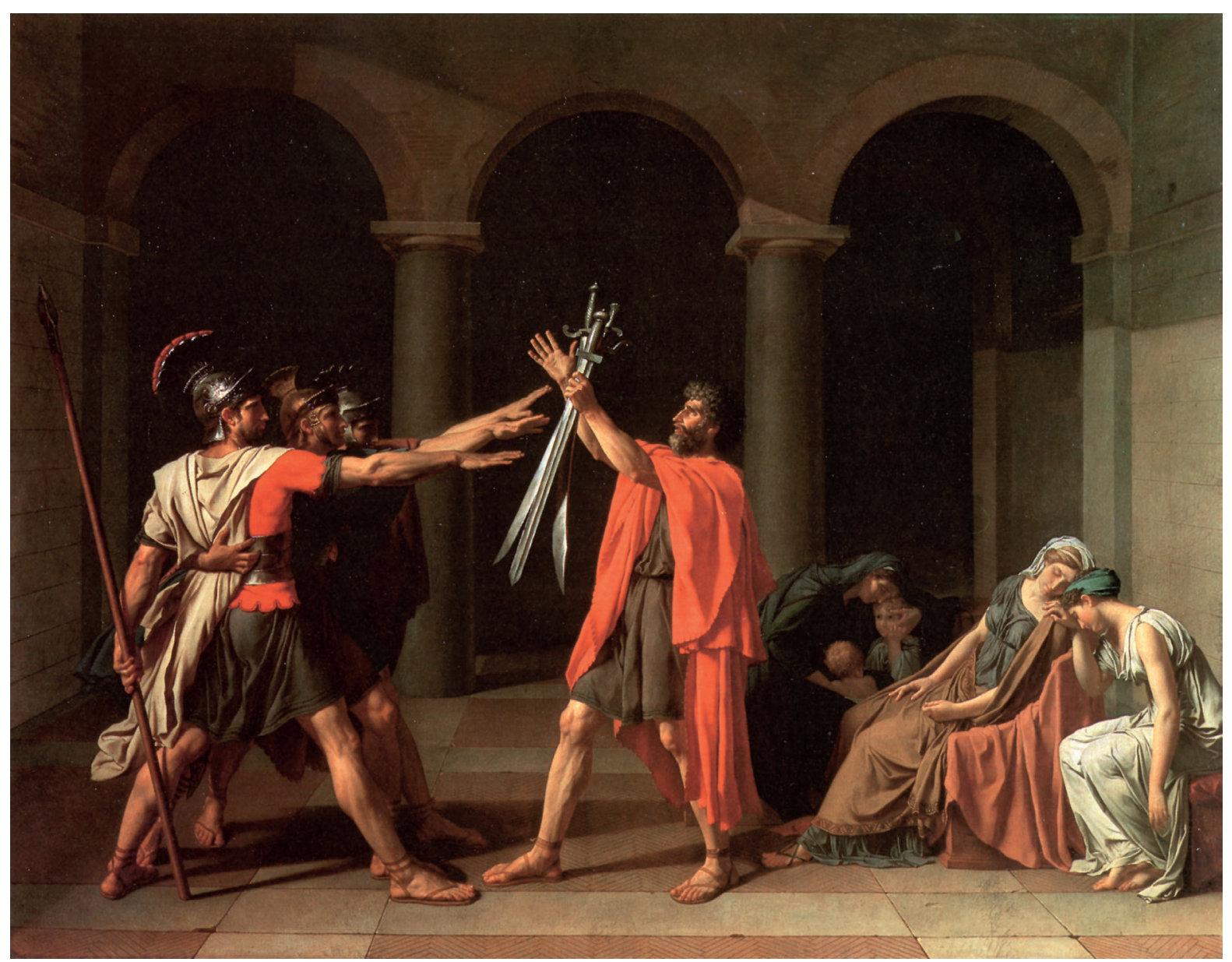

5 Jacques-Louis David, Le Serment des Horaces, 1784, Öl auf Leinwand, $330 \times 425 \mathrm{~cm}$. Paris, Musée du Louvre

Diese Bildidee ist nicht gänzlich neu - und auch nicht unmittelbar aus dem revolutionären Prozess heraus geboren. Vielmehr hatte sich David schon mit seinem 1781 - 1784 entstandenen und $1785 \mathrm{im}$ Salon ausgestellten Serment des Horaces als Spezialist für uniformisierende Körperkonditionierung ausgewiesen (Abb. 5). ${ }^{11}$ Auch hier ging es - mit klarem Bezug auf Johann Heinrich Füsslis Rütli-Schwur um unverbrüchliche unité, unlösbare solidarische Geschlossenheit, aber auch Untrennbarkeit bis zur endgültigen Durchführung eines historisch-politischen Auftrags: Die Tragik der Situation besteht darin, dass es sich bei den durch Los zum Stellvertreterkampf zwischen Rom und
Alba Longa Auserkorenen ausgerechnet um je drei Brüder handelt, die familiär über Verlöbnisse und Hochzeiten miteinander verbunden sind. Daher müssen sie in ihrer Kampfesmoral im Vorfeld besonders stark eingeschworen werden. David schmiedet die drei Horatierbrüder, die völlig identisch aussehen, durch ihren Umfangungsgestus und die Parallelisierung ihrer Bein- und Armhaltungen zum Drillingsbund eines kampfbereiten Gesamtkörpers zusammen; er lässt sie zur Bildformel stahlharter Entschlossenheit erstarren. Sein Gemälde liefert ein dann von der Terreur gerne aufgegriffenes Emblem für kompromisslos richtige Gesinnung, die sich im Bild in den metallischen Linien der Schwer- 
ter, den muskulös angespannten Beinen, die im rechten Winkel gespreizt sind, ${ }^{12}$ und in der spartanischen Konstruktion des Raumes manifestiert, in dem die Schwurszene wie auf einer Bühne saufgeführt` wird. Die gerade Linie symbolisiert rigide Tugend, die keine Kompromisse kennt. Die Körper sind dazu konditioniert, unerschütterlich das republikanische Ideal der frühen römischen Republik bis in den Tod aufrecht zu erhalten..$^{13}$

Auch das nach dem >Vatermord zösischen König am 21. Januar 1793 neu etablierte, revolutionäre Familienmodell allumfassender fraternité, die als Führungskollektiv ${ }^{14}$ an die Stelle der patriarchalischen Monarchie treten sollte, ist im Schwur der Horatier bereits angelegt: Der Vater in der Bildmitte schirmt die Söhne von der Gruppe rechts ab, er bildet eine undurchdringliche Barriere zu den Frauen und Kindern, denen er den Rücken zukehrt und die sowohl im Kolorit als auch in der weichen, gebeugten Formgebung das völlige Gegenteil zu der kampfbereiten männlichen Vernichtungsmaschinerie links darstellen. ${ }^{15}$ Der fanatische Aktionismus der "Brüderbande,${ }^{16}$ deren Phalanx aggressiv nach außen strebt, drängt die Frauen mit ihren Ängsten an den äußersten Rand des Geschehens. Familiäre Rücksichten, die auf den biologischen Fortbestand der Familie ausgerichtet wären, werden dem durch spartanische Erziehung an die Söhne vermittelten Tugendideal des republikanischen Ruhms und der männlichen Ehre geopfert, die weit höher im Wertekanon anzusiedeln sind, weil sie nicht materiell-prokreativ, sondern idealistisch $\mathrm{Zu}$ kunft schaffen. Hier ist sichtlich ein heroisches Zeitalter angebrochen, in dem es keine Vermittlung mehr zwischen den früheren Sphären gibt: Die nur noch ihrer eigenen ratio republikanischer Tugendhelden folgenden Männer sind dem Einfluss der Frauen längst entrückt, sie sind innerlich schon weit weg vom heimischen Herd, die traditionelle familiäre Triade ist gesprengt. ${ }^{17}$ Der sich absolut geradlinig präsentie- renden männlichen Willenskraft hat David in marginalisierter Position zwei Pyramidalgruppen aus Frauen und Kindern gegenübergestellt. Diese folgen dem Bildschema der Heiligen Familie, wie es prototypisch auf Raffaels Heiliger $\mathrm{Fa}$ milie aus dem Hause Canigiani zu finden ist; sie versuchen, die Intaktheit der familiären Dreierbeziehung vergeblich aufrechtzuerhalten, da das zentrale Element, der Mann, fehlt. Dieser hat sich für die unité des ebenfalls aus drei Elementen zusammengesetzten Brüderbundes entschieden, in dem absolute Gleichheit und Gleichwertigkeit herrschen. Aus der ödipalen Triade ist er ausgestiegen, allerdings hatte ja auch Josef in der Dreierkonstellation der Heiligen Familie bereits eine nicht sehr überzeugende Vaterfigur abgegeben. ${ }^{18}$

Für private Befindlichkeiten, die eine eindeutige Parteinahme für das bonum commune $\mathrm{zu}$ umgehen versuchen, ist in diesem strikt republikanischen System kein Platz mehr. In seinem 1789 noch in königlichem Auftrag gemalten Bild Les Licteurs rapportant à Brutus les corps de ses fils (Abb. 6) ${ }^{19}$ hat David eine Art Emblem für die Strenge und Gnadenlosigkeit der republikanisch-patriotischen Ideale geschaffen, die zum Zweck des Erhalts der neuen Staatsform unbedingt einzuhalten sind. Das Gemälde zeigt Lucius Iunius Brutus, den Begründer der römischen Republik, in seinem Haus, und zwar in dem Moment, als ihm die Leichname seiner beiden Söhne Titus und Tiberius zur Bestattung gebracht werden. Er selbst hatte sie wegen des Verdachts einer antirepublikanischen Verschwörung und des Versuchs der Wiedereinsetzung der gerade überwundenen Königsmacht hinrichten lassen. Weder die Tat selbst noch die Entscheidungsnöte des Brutus im Vorfeld dieses die Vaterliebe zugunsten der Vaterlandsliebe suspendierenden Handelns hat David dargestellt, sondern den fruchtbaren Moment der Reflexion, in dem die Gestalt des Brutus an psychologischer Tiefendimension gewinnt, da er über die Folgen seiner Aktion nachdenkt. ${ }^{20}$ 


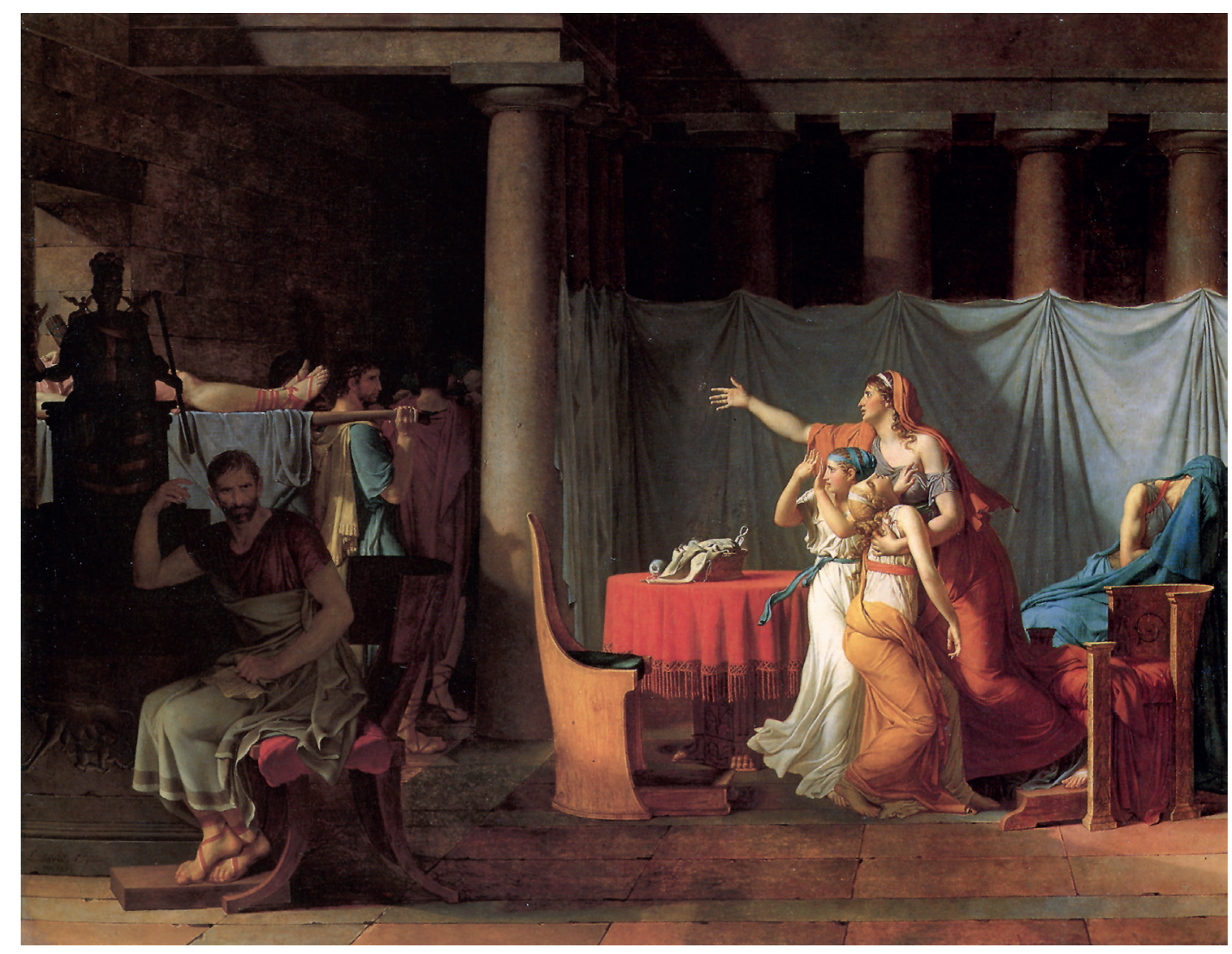

6 Jacques-Louis David, Les Licteurs rapportant à Brutus les corps de ses fils, 1789, Öl auf Leinwand, $323 \times 422 \mathrm{~cm}$. Paris, Musée du Louvre

Doch scheinen ihm keinerlei Zweifel über die Richtigkeit seiner Entscheidung zu kommen. Grimmige Entschlossenheit und höchste Anspannung (bis in die Zehenmuskulatur) zeigen die Unvermeidlichkeit des Urteils im Sinne der republikanischen Ideale. Die Aufopferung der individuellen Zukunft - der eigenen männlichen Nachkommen - für den Erhalt der Republik ist als gerechtfertigt dargestellt. Zugleich marginalisiert ihn die Unmenschlichkeit dieser von ihm allein, aber im Sinne der Staatsräson notwendigerweise getroffenen Entscheidung im Bild wie im Familienverband. Er ist am Rand vereinzelt und vereinsamt, während das leere Zentrum des Bildes von der emotionalen Erstarrung erfüllt zu sein scheint, die seine Entscheidung bei allen anderen Beteiligten hervorruft. Über Brutus lauert die nur im Schattenriss gegebene, starre, schwarz-bedrohliche Statue der Dea Roma, die das gnadenlose Gesetz als abstrakt-rationales Prinzip und damit die Grundlage des späteren republikanischen Tugendpostulats und Robespierres rousseauistisch gestützter vertuIdeologie des sogenannten "Incorruptible« repräsentiert, welche sich den Brutus zu einer ihrer Inkunabeln wählten. Dieser systematische Tugendterror basierte auf Rousseaus Prämisse, dass der Mensch erst dann ganz zu sich komme, wenn er entweder den natürlichen Menschen in sich auspräge oder aber die Staatsraison derart internalisiere, dass er als vollkommener Staatsbürger zum Besitz des Staates wird. ${ }^{21}$ Das Gesetz, in dem sich unparteiische Gerechtigkeit manifestiert, und das Gemeinwohl sind über jedes persönliche Interesse zu stellen - hierzu ist freilich nur ein Mann in der Lage. Das weibische 
Geschrei seiner Frau und seiner der Ohnmacht nahen Töchter, die sich bacchantinnengleich in hysterischen Klagerufen ergehen und so ihrer expression des passions ungezügelt freien Lauf lassen, stören ihn (so David in der Selbstbeschreibung seines Bildes) in seiner stoischen und gefassten Trauer auf. ${ }^{22}$

Auch in diesem Bild geht ein nie mehr zu kittender Riss durch die Familienkonstellation, auch hier verläuft er entlang den Geschlechtergrenzen, und auch hier kehrt der Stuhl, der die beiden Sphären trennt, den Hauptakteuren den Rücken zu, er schirmt und schließt allerdings im Gegensatz zum Vater der Horatier den weiblich konnotierten Bereich ab. Der von Männern beherrschte öffentliche Raum dringt mit den Leichen in den privaten, in seiner architektonischen Gestaltung wie in seiner Dekoration weiblich geprägten ein $^{23}$ und vernichtet diesen und seine Schutzfunktion - bezeichnenderweise spielt die Szene im Atrium einer römischen Domus oder Villa, das ein halböffentlicher Ort des Übergangs von Außen nach Innen war. Nur vermeintlich sind die Frauen durch den mit hellen Tüchern abgehängten Raum im Raum vor dem Eindringen der Öffentlichkeit in die häusliche Intimität geschützt, die als solche durch das Stillleben des Handarbeitskorbes (kalathos) auf dem Tisch gekennzeichnet ist. ${ }^{24}$ Die basenlosen dorischen Säulen - schon in der antiken Säulenordnung `männlich konnotiert - signalisieren wie in den Horatiern nach außen hin wehrhafte Strenge und strikte Gesetzestreue und sind nur notdürftig nach innen hin kaschiert. Seit Poussins Mort de Germanicus rufen solche Vorhänge vor Säulen oder Pilastern das Todesthema auf. Tatsächlich ist die vollständig politisierte $\mathrm{Au}$ ßenwelt in dieser Darstellung schon längst ins Innerste der Familienstrukturen vorgedrungen, wie die durchgängig republikanisch-trikolorische Farbgebung der rechten Bildhälfte demonstriert. ${ }^{25}$ Der Rückzug in die Privatheit der Familie ist hier unmöglich geworden: In der Republik ist alles öffentlich, alles res publica, und deren Zielen unterworfen, jede Verfehlung wird öffentlich geahndet. Das neue politische System, das sich dann während der Terreur zu einem veritablen Überwachungsstaat radikalisieren sollte, fordert die totale und gnadenlose Unterwerfung unter seine unmenschlichen Ideale.

\section{Den eigenen Kopf retten - mit einem Selbstporträt}

Doch mit dem Sturz Robespierres am 9. Thermidor $1794^{26}$ war die Zeit der jakobinischen Triumphzüge und Festinszenierungen vorbei, und der Stern des politisierenden Künstlers David sank rapide. Noch am Tag vor der Festnahme Robespierres, dem 8. Thermidor, soll David sowohl im Wohlfahrtsausschuss als auch im Jakobinerclub gesagt haben, er wolle, wenn es zum Äußersten käme, solidarisch den Schierlingsbecher mit ihm teilen: »Si tu bois la ciguë, je la boirai avec toi. $^{27}$ Davon war nach der Hinrichtung von Robespierre und dessen engsten Parteigängern nicht mehr die Rede; ${ }^{28}$ er ließ diesen Kelch doch lieber an sich vorübergehen. David selbst hatte sich durch angeblich krankheitsbedingte Nichtanwesenheit im Nationalkonvent am 9. Thermidor der Verhaftung und Schlimmerem entziehen können. ${ }^{29}$ Er bestritt jegliche Wahlverwandtschaft mit dem jetzt sogenannten $>$ Terroristen . Dieser habe ihn getäuscht und missbraucht, indem er ihn zu Handlungen gedrängt habe, die er aus freien Stücken niemals begangen hätte. Außerdem habe Robespierre um seine Freundschaft gebuhlt und nicht umgekehrt: »citoyens, je vous assure qu'il me faisait plutôt la cour qu'on ne peut dire que je la lui aie faite. $\aleph^{30}$

Am 16. November 1794 erklärte er: »Il n'y a qu'un homme vraiment ami des arts qui puisse apprécier à sa juste valeur le cœur et la tête d'un artiste. Il sait mieux qu'aucun autre que son imagination exaltée l'entraîne presque toujours au-delà du but. Je le savais moi-même, je 


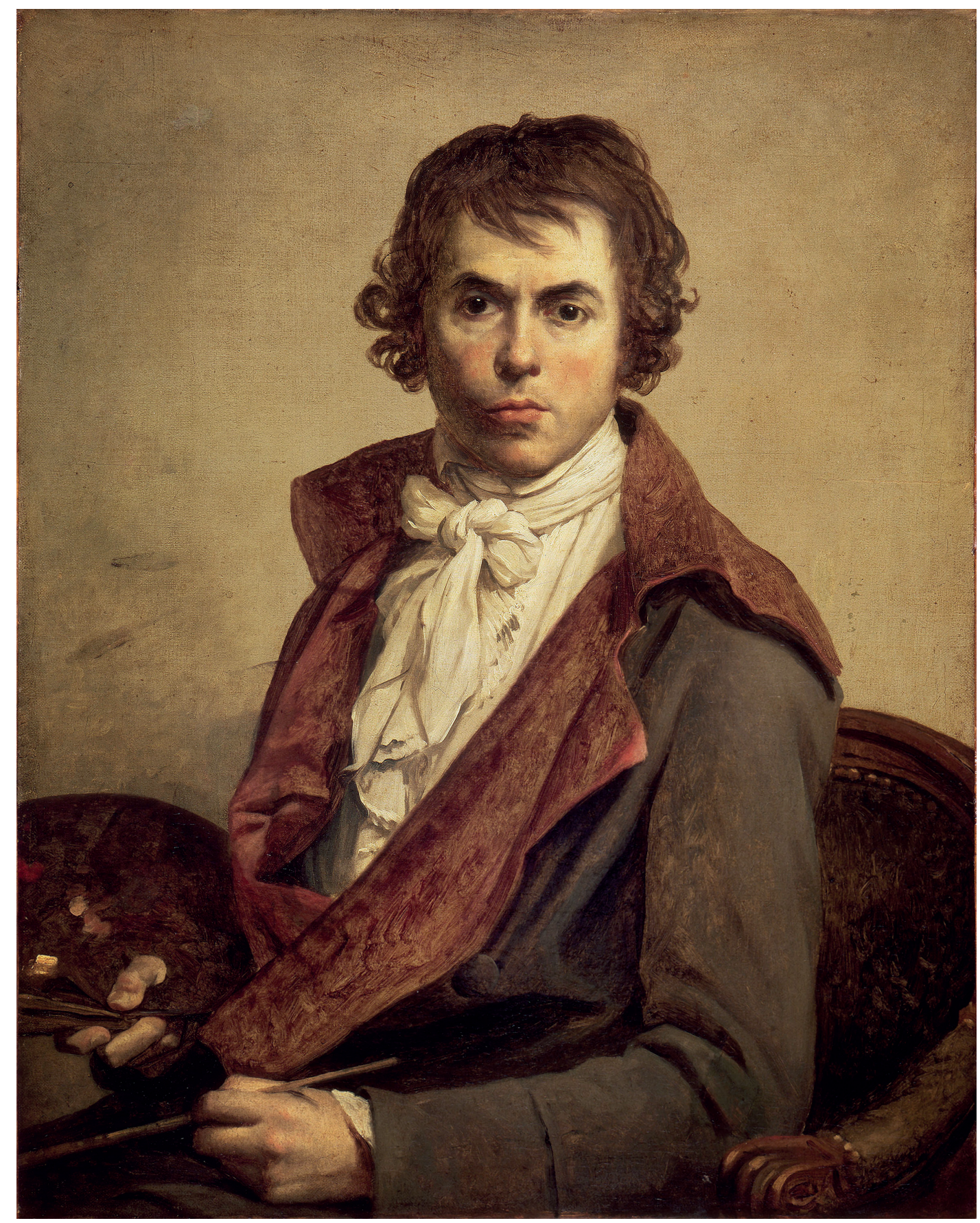

7 Jacques-Louis David, Autoportrait, 1794, Öl auf Leinwand, $81 \times 64$ cm. Paris, Musée du Louvre

croyais m'en être garanti, quand l'abîme ouvert sous mes pas était prêt de m'engloutir. Les méchants, combien ils m’ont abusé! n'allez pas cependant croire que j'aie jamais pu participer à leurs infâmes complots. Non, non, mon cœur est pur, ma tête seule a failli.. ${ }^{31}$ Wenn er selbst verführbar gewesen sei, dann nur, weil er wie alle Künstler von einer potenziell überschießenden 
Einbildungskraft dominiert sei. Zusammen mit seiner ausgeprägten Emotionalität sei sie ihm in der Welt der Politik zum Verhängnis geworden - die Eigenschaften des Künstlers hätten die in der politischen Sphäre herrschende ratio, den kühl kalkulierenden Verstand, überwogen. David machte demnach seine exzessive, überschießende und bisweilen die Kunstgrenzen sprengende imagination, ${ }^{32}$ die in der klassizistischen Kunstkritik traditionell alle Transgressionen der normativen Ästhetik zu verantworten hatte, für seine Fehler verantwortlich. Politisch gesehen, so das Argument, hatte er das Herz auf dem rechten Fleck, falsch war allein, künstlerische Maximen auf die Politik übertragen zu wollen und die verschiedenen Handlungsbereiche zu vermischen, statt bei seinem eigentlichen Metier zu bleiben. ${ }^{33}$

In der Zeit seiner ersten Inhaftierung zwischen dem 2. August und dem 28. Dezember $1794^{34}$ schlugen sich Davids Bemühungen, seinen Kopf vor der Guillotine zu retten, in seinen selbstlegitimierenden Schreiben an den Nationalkonvent nieder. Er nutzte diese Zeit der erzwungenen Muße aber auch, um ein Selbstporträt zu malen (Abb. 7), ${ }^{35}$ mit dem er seinen ultimativen Unschuldsbeweis zu erbringen gedachte. ${ }^{36}$ Malen konnte er während der Haft, da er den ersten Monat unter vergleichsweise komfortablen Bedingungen im ehemaligen Hôtel des Fermes in der Rue de Grenelle verbrachte, wo ihm das leerstehende Atelier eines seiner für die Armee rekrutierten Schüler zur Verfügung gestellt wurde. Bezeichnenderweise dachte er in dieser Zeit auch darüber nach, den aufgegebenen Ballhausschwur - und damit ein politisch unverdächtiges Thema vor allem Abgleiten der revolutionären Ideen in die Terreur - doch noch zu vollenden und somit erneut seine republikanische Haltung zu dokumentieren. Dieses Projekt wurde bekanntlich nie ausgeführt. Als gänzlich unpolitisch schließlich stilisierte sich David, indem er den Ausblick aus dem Fenster seiner maison d'arrêt in den Jardin du Luxem- bourg malte, das einzige autonome Landschaftsgemälde, das überhaupt von ihm erhalten ist. ${ }^{37}$

Das malerische Hauptargument im Selbstporträt aus dem Louvre von 1794 für die Unbescholtenheit des hier Dargestellten scheint zu lauten: Seht mich an, Mitbürger, haltet Ihr mich wirklich solcher Verbrechen für fähig? Die einzigen Waffen zur Verteidigung meiner Unschuld, über die ich verfüge und die ich überhaupt zu handhaben vermag, sind meine Palette und mein Pinsel. Ich bin nichts als ein Künstler, kann mich also gar keiner politischen Vergehen schuldig gemacht haben. ${ }^{38}$ - Kein législateur tritt dem Betrachter hier entgegen, sondern ein Maler, der allein nach den Gesetzen der Kunst zu richten und ausschließlich dem ästhetischen Urteil unterworfen ist. Der Blick dieses »honnête homme«, wie David sich selbst bezeichnet, ${ }^{39}$ hat nichts Schuldbewusstes, sondern eher etwas betont Neutrales, unbewegt Unerschütterliches, wenn nicht Überhebliches. Aus dem Selbstbildnis spricht die absolute Sicherheit, sich nicht verteidigen zu müssen, da das Umfeld ohnehin nicht satisfaktionsfähig ist, wie der leicht arrogant-trotzige Blick andeutet. David schwankt in seinem Ausdruck im Bild zwischen Selbstbehauptung und Unschuldsbekundung. Er scheint dem Betrachter beteuern zu wollen, dass er alles offenlegt, und zwar mit den ihm zur Verfügung stehenden künstlerischen Mitteln, die er, der von seinen Freunden als "gloire de l'Ecole française « ${ }^{40}$ gefeiert wurde, wie kein anderer beherrscht. Zugleich drängt ihn sein ignorantes Umfeld dazu, ein wahres Bild von sich selbst zu malen, da seine Feinde sein Verhalten in verleumderischer Absicht in den dunkelsten Farben zeichnen und ihn so in seiner Selbstdarstellung zu einem weiteren Revolutionsmärtyrer werden lassen: »Ah! que des ennemis cruels qui me poursuivent, et qui, en abusant des circonstances, osent me peindre des plus sombres couleurs, descendent dans l'intérieur de ma vie, et qu'ils en exposent, s'ils le veulent, le tableau fidèle sous les yeux du public. «11 
Die Faktur des Selbstporträts betont, dass hier nichts kaschiert werden soll, da das dargestellte Subjekt nichts zu verbergen hat. Der Malakt selbst wird absolut faktengetreu dokumentiert, in einer einmaligen, konkreten historischen $\mathrm{Si}$ tuation, in der der Maler das Bild eins zu eins abmalt, das sich ihm im Spiegel zeigt. Der tatsächlich mit der Rechten gehaltene Pinsel ist hier wie im Spiegelbild in seiner linken Hand zu sehen. ${ }^{42}$ Durch diese naturalistische Offenheit versucht David, im Bild seine Unschuld erstrahlen zu lassen, "faire éclater mon innocence ${ }^{43}$ »je n'ai rien à me reprocher « ${ }^{44}$ und er empfiehlt sich gleichzeitig als unbestechlicher Dokumentator des Revolutionsgeschehens, dessen Geschichte er allein adäquat zu malen in der Lage ist. Die ungeglättete Handschrift bleibt im Bild sichtbar, genau so, wie sie auf die Leinwand gebracht wurde - selbst Fingerabdrücke sind in der Farbe fixiert. David versucht, in der Faktur seines Bildes den Eindruck zu erwecken, als kehre er sein Innerstes nach außen - wie das Innere seines Mantelaufschlags, ein Meisterstück autonomer Farbmalerei und Oberflächengestaltung. Auch die Mittel, die er zu seiner Rehabilitierung einsetzt, Pinsel und Farben, werden als unverdächtig vorgezeigt. Der dargestellte Moment ist aufgrund des monochromen Hintergrunds und der Fixierung im Spiegelbild ebenso ort- wie zeitlos; der Porträtierte will sich als geschichtslos, vergangenheitslos präsentieren, er tritt dem Betrachter als reine und unbelastete Identität entgegen.

Doch David geht noch einen Schritt weiter in dieser Simulation eines absolut abbildgetreuen Naturalismus. Er gibt selbst seine Defekte preis: Die Exostase, die (erneut gespiegelt) links an seiner Wange zu sehen ist, eine sich nach außen abbildende, krebsartig wuchernde Knochensubstanz, die Davids rechte Gesichtshälfte entstellte und ihn in seiner sprachlichen Artikulation behinderte, wird vom Künstler hier weniger als monströses Stigma denn als individuelles Markenzeichen, ja als Auszeichnung des Porträtier- ten in seiner Einzigartigkeit gemalt. Zugleich ist diese Deformation aber auch genau diejenige Stelle im Bild, die durch ihre Verschattung darauf verweist, dass dieses Gemälde nur eine mit höchster Virtuosität erzeugte Pose der Offenherzigkeit ist, eine mit künstlerischen Mitteln erzeugte Illusion. Denn selbst wenn man davon ausgehen darf, dass sich die Entstellung im Laufe der Zeit verstärkte - wie in der post mortem 1826 - 1831 entstandenen Büste des Malers von François Rude dokumentiert -, so bildete sie sich 1794 bereits deutlicher im Gesicht Davids $\mathrm{ab}$, als das Selbstporträt den Betrachter glauben machen möchte. In der Schönung seiner Deformation mit malerischen Mitteln verrät sich der Maler als Manipulator desjenigen Images, das er von sich erzeugen will: Dieser Mann kann politisch gar nicht zur Rechenschaft gezogen werden, da die Politik nicht sein angestammtes Metier ist. Er hat sich nur als Künstler zu verantworten, und er verdient um dieser seiner Professionalität willen Schutz vor politischen Anschuldigungen.

An verschiedenen Stellen des unvollendet gebliebenen Gemäldes scheint das Material des Bildträgers, die Leinwand, durch. Nachdem David im August 1794 aus den komfortablen Haftbedingungen in der Rue de Grenelle ins Luxembourg überführt worden war, arbeitete er an seinem Selbstporträt nicht mehr weiter, und auch nach seiner Entlassung aus der Haft hat er die Arbeit daran nicht wieder aufgenommen. Das non finito des Bildes scheint ihn nicht gestört zu haben, dokumentiert es doch, dass der Malakt unter Zeitdruck stattgefunden hat. Das Gemälde trägt in seinem unfertigen Zustand dauerhaft das Signum des Authentischen. Zugleich wird das Bild damit als reine Oberfläche indiziert, die vom Künstler nach seinem Gutdünken übermalt oder auch frei gelassen werden kann und die in der semantischen Übertragung wohl auch nur die Oberfläche der Identität des Dargestellten preisgibt. Das Eigentliche ist das künstlerische Handeln, scheint das Bild sa- 
gen zu wollen; der Künstler schafft mit seiner Malerei die einzig gültige Realität, die den Blick bis auf den Grund der Tatsachen nicht verstellt. Sein Gewissen scheint so rein zu sein wie sein weißes Hemd ${ }^{45}$ und das seinen Hals schützende Tuch. Dieses signalisiert, nichts im Dunkeln lassen zu wollen, sondern alles ans aufklärerische Licht zu bringen, die Wahrheit offenzulegen, ohne sich allzu offenherzig zu präsentieren. Die houppelande und die sweiße Wester, die von keiner Kokarde oder einem anderen revolutionären Abzeichen geschmückt ist, ${ }^{46}$ umhüllen den Künstler derart, dass die eigentlichen Körperkonturen nicht mehr auszumachen sind. ${ }^{47}$ Zur Entblößung seiner Feinde führt David - in rousseauschem Impetus - das Postulat schonungsloser Offenlegung an. So heißt es in seinem Selbstrechtfertigungsbrief vom 14. Floréal 1794, der an verschiedenen Stellen den Angriff als beste Verteidigungsstrategie einsetzt: »Oui, je vous poursuivrai à mon tour, calomniateurs effrontés, ennemis irréconciliables de l'ordre, de la justice et de la probité. C'est en vain que vous vous enveloppez de ténèbres; je porterai la lumière dans les replis les plus cachés de votre cœur, je découvrirai les ressorts secrets qui vous font mouvoir, et $j$ 'imprimerai sur vos fronts le caractère hideux des passions qui vous agitent. $\ll^{48}$

Bei alledem heißt Offenheit aber gerade nicht Selbstpreisgabe, sondern Selbstbehauptung als wahrer Künstler, der sogar in Extremsituationen, im Gefängnis, seinen geistesaristokratischen $\mathrm{Ha}$ bitus der Betrachterlenkung und -dominierung aufrecht erhält: Kaltblütig und selbstbeherrscht richtet er seinen Künstlerblick aus dem Bild heraus. Ihm eignet eine privilegierte Sicht auf die Wahrheit, da nur derjenige, der sich selbst malt, so auf sein Ich blicken kann. David beherrscht seine Selbstdarstellung bis ins letzte Detail; er meistert seine Repräsentation im Bild mit professionellen Mitteln, die allein ihm als Künstler zur Verfügung stehen. Mit einer raffinierten Strategie erzeugt er zugleich im Betrachter den Eindruck, das Selbstbildnis sei speziell für ihn gemalt ${ }^{49}$ - aber der Porträtierte spiegelt nur vor, den Betrachter zu sehen. Tatsächlich ist sein Blick minimal nach rechts, auf sich selbst, nämlich auf sein Spiegelbild gerichtet, das ihn einer durch die äußeren Umstände erzwungenen Befragung zu unterziehen scheint. Das Selbstporträt als Produkt dieser Inquisition und als eigenmächtige Neudefinition des Dargestellten gibt vor, die Fragen nach politischer Kompromittierung, nach Schuld oder Unschuld nach bestem Wissen und Gewissen zu beantworten. Tatsächlich aber führt David im Bild nur einen inneren Monolog mit sich selbst, dessen Inhalt dem außenstehenden Betrachter für immer verschlossen bleibt. Er kann die Authentizität der Identitätsbekundung des hier Dargestellten nicht überprüfen, denn die vérité des Malens erschließt sich nur dem >Profiı, der die Arkana seiner Profession, der Kunst, beherrscht und als Geheimwissen zu hüten weiß. Auch kann sich der Maler eben nur in dem ihm vertrauten Medium, der Malerei, adäquat ausdrücken, während die Selbstrechtfertigung im Medium der Sprache misslingen muss - wegen der durch die Exostase hervorgerufenen Artikulationsstörung, aber auch als das durch die Politik der Terreur diskreditierte Ausdrucksmittel. ${ }^{50}$

Im Selbstporträt als Bekenntnisbild, in dem David sich selbst eine neue Identität - die eines gänzlich Unpolitischen ${ }^{51}$ - zu schaffen sucht, wendet er naturgemäß auch seinem Werkzeug, der Palette, die passende Aufmerksamkeit zu. Auf ihr präsentiert sich das malerische Primärmaterial in Rohform. Sie erscheint als Ort reiner Farbmalerei, an dem jede Form aufgelöst ist, ${ }^{52}$ und markiert dadurch den unbelasteten Nullpunkt autonomer künstlerischer Entfaltung, von dem aus alles möglich ist, von dem eine künftige, unverdächtige Formgebung ihren Ausgang nehmen kann. Zugleich demonstriert sie durch ihre Faktur, dass der Maler nicht nur in der Lage ist, Formen zu schaffen, sondern auch, Bestehendes zu deformieren, ja malend 


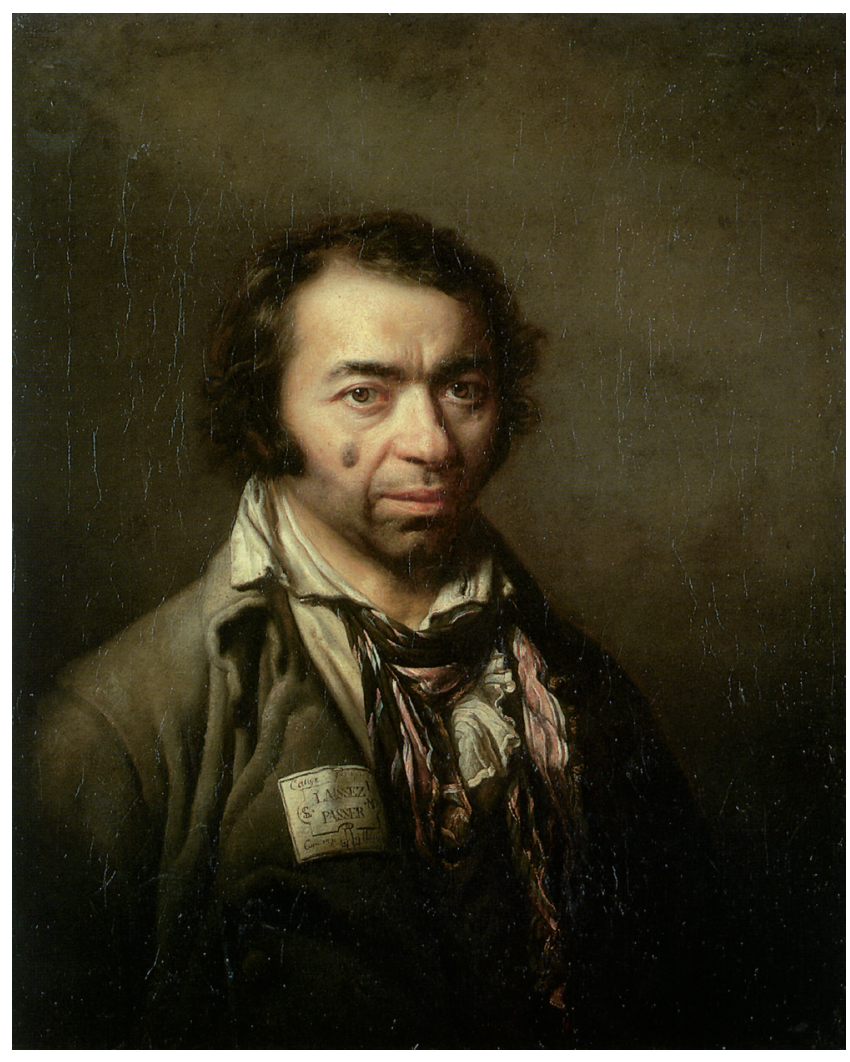

8 Pierre-Nicolas Legrand de Sérant, Joseph Cange, commissionnaire de la prison Saint-Lazare à Paris, 1794, Öl auf Leinwand, $70 \times 56 \mathrm{~cm}$. Vizille, Musée de la Révolution française

auszulöschen, vormalige Repräsentationen seiner selbst ungeschehen zu machen. ${ }^{53}$ Er präsentiert sich im Bild als ein unbeschriebenes Blatt: Der Gesichtsausdruck ist bewusst uneindeutig gehalten, er entzieht sich einer Festlegung im Sinne der physiognomischen Tradition. Hier ist keine tête d'expression im Sinne Le Bruns gegeben, ${ }^{54}$ der Dargestellte will sich nicht festlegen lassen; das innere Drama und die psychischen Nöte dieses modernen Subjekts sind in den simplifizierenden Stereotypen der Physiognomiker nicht mehr adäquat darstellbar. ${ }^{55}$ In seiner Ausdruckslosigkeit und Bedeutungsentleerung scheint der Porträtierte die »Révolution glacée» zu spiegeln. ${ }^{56}$ Sein Gesicht bildet - hierin der Palette vergleichbar - einen Nullpunkt der passions, von dem aus ein unbelasteter Neubeginn der Künstlervita möglich ist. ${ }^{57}$
David stilisiert sich als weiteren Revolutionsmärtyrer, der sich seiner Selbstaussage zufolge bereits als unmittelbare Reaktion auf die vorgeblichen Verleumdungen nach den Thermidortagen $^{58}$ ins innere Exil eines solchen passionslosen, emotionalen Nullzustandes begeben hatte..$^{59}$ Jetzt begeht er auch den expliziten Verrat am verstorbenen >Bruder Robespierre: »Ainsi, avant le 9 Thermidor, j'ai pu, sans être coupable, marcher dans la ligne révolutionnaire tracée par l'opinion dominante à cette époque, et lorsque j'ai été appelé devant les trois Comités réunis pour y rendre compte de ma conduite, j'ai démontré que l'erreur dans laquelle j'avais été entretenu sur les vues secrètes de Robespierre et de ses complices était l'ouvrage de la Convention elle-même, abusée par le faux éclat de leur patriotisme. [...] quelle surface immense je présente aux traits des passions qui grondent autour de moi! Mais contre ces traits je m'armerai d'une égide qui sera toujours impénétrable, c'est celle d'une vie pure, désintéressée, exempte des passions qui ont déshonoré la carrière de ceux qui ne furent qu'un moment les sincères amis du peuple, d'une vie sur-tout étrangère à tout autre sentiment qu'à celui de la liberté et à l'amour de la patrie. ${ }^{60}$ Erst nach diesem Moment der Selbstvergewisserung, dessen Ergebnis ein Selbstbildnis gänzlich ohne Pathos und ohne expression des passions ist, ${ }^{61}$ kann der Meister wieder neu und unkompromittiert einsetzen mit der Ausübung seiner Profession. In den Selbstverteidungsschriften Davids ist die Verurteilung der auf Abwege verleitenden passions omnipräsent. $^{62}$

In den Beständen des Musée de la Révolution française in Vizille befindet sich ein Gemälde von Pierre-Nicolas Legrand de Sérant aus dem Herbst 1794 (Abb. 8), das hier erstmals mit dem David'schen Selbstporträt verglichen werden soll..$^{63}$ Der Dargestellte, Joseph Cange, war commissionnaire (eine Art Hilfsbote) für die Inhaftierten der Prison Saint-Lazare, der Frau und Kind eines der Häftlinge heimlich finanziell un- 
terstützte und damit in einem anonymen Akt der pietas die Sorgen des Familienvaters milderte. Seine Geschichte wurde nach der Freilassung des Inhaftierten bekannt, diverse Libretti griffen das Sujet auf, die Druckgraphik verewigte es und der Nationalkonvent würdigte es als exemplum virtutis. Cange wurde in der Spätphase der Revolution zum edlen Sansculotten stilisiert, der trotz seiner strikt durchgehaltenen republikanischen Ideale seine Menschlichkeit nicht vergessen und in der guten Tat seine Humanität manifestiert hatte. Zwar ist er zerlumpt und hässlich, sein Gesicht von einem überdimensionalen Melanom entstellt (das sich an der gleichen Stelle wie Davids Tumor befindet), aber in seinem Inneren ist er gut und damit schön, und sein trikolorisches Halstuch dokumentiert, wenn auch schlampig gebunden, seine von Grund auf richtige Gesinnung eines »vertueux citoyen «, deren Ruhm alle politischen Krisen überdauern wird. Genau das ist das Selbstbild, das auch David in seinem Selbstporträt von sich erzeugen wollte. Ob Legrand Davids Bild je gesehen hat, muss allerdings dahingestellt bleiben. Zu sehr unterscheidet sich das Rollenmodell des guten Sansculotten von Davids Bestreben, sich als unbeschriebenes Blatt zu stilisieren. Generell haben wohl nur sehr wenige Betrachter aus Davids unmittelbarstem Umfeld das Selbstporträt, Dokument seiner Identitätskrise, zu Gesicht bekommen, das er in seinem Atelier behielt und später seinem Schüler Jean-Baptiste Isabey schenkte.

\section{Väter und Söhne - Lehrer und Schüler: eine alternative Genealogie}

Doch David musste sich nicht nur in seinem Selbstporträt eine neue Identität ermalen, er sah sich auch genötigt, sich eine neue Genealogie zu erschaffen, indem er sich einen autonomen Familienroman schrieb. Nach dem $>$ Vatermord an Louis XVI war an die zentrale Stelle des souveränen Herrschers im Staat ein pluralistisch-egalitäres Modell des unverbrüchlichen Brüderbundes einer die Nation einenden fraternité getreten, das in seiner euphorisch vorwärtsdrängenden Dynamik, die sich nicht mehr nach der Vergangenheit umblickte, die Mordtat vergessen lassen sollte. Generell ist während der Französischen Revolution die Abwertung bzw. Ausgrenzung der Familie als Erziehungsinstitution zu konstatieren, deren Maximen Robespierre am 13. Juli 1793 dem Nationalkonvent in seinem totalitären Erziehungsplan für die gesamte Nation vorstellte. Er hatte ihn anhand der Vorgaben des Revolutionsmärtyrers Le Pelletier entwickelt, weitete sie jedoch aus und verschärfte sie. Das erste Ziel der hier konzipierten Gesellschaft mit totalitärem Avantgarde-Anspruch musste naturgemäß die (Um)Erziehung ihrer Bürger zu "neuen Menschen" sein, damit diese sich fürderhin reibungslos und möglichst nutzbringend in das neue System integrieren ließen und sich willig unter »das Joch einer strikten Disziplin« im Sinne des Gemeinwohls beugten. ${ }^{64}$ Historisches Vorbild für den Erziehungsplan war die staatliche Erziehung der männlichen Spartaner und ihre Überantwortung an >Vater Staat` im Kleinkindalter, wie sie beispielsweise Jean-Pierre Saint-Ours auf seinem Gemälde Le choix des enfants de Sparte im Salon von 1791 illustrierte. ${ }^{65}$

Für David war nun allerdings spätestens seit dem Verrat an seinem `Bruder Robespierre, also nach dem 9. Thermidor 1794, das Modell der fraternité nicht mehr tragfähig. ${ }^{66}$ Er ersetzte es durch ein unverdächtiges neues, da kunstinternes Modell, indem er das Vater-Sohn-Verhältnis durch das Lehrer-Schüler-Modell substituierte: "j'ai vu se rallier autour de moi ceux dont l'amitié doit m'être d'autant plus chère que je me suis toujours porté vers eux par des témoignages plus marqués d'attachement et de prédilection. Les élèves de l'art que je professe, ces jeunes artistes, dans lesquels je me verrai revivre, ont signalé envers moi cette piété filiale qui lie l'élève 
à son maître par des chaînes aussi fortes que les liens de sang, puisqu'elles se rattachent aux plus nobles sentiments du cœur humain. J'ai vu leur tendre sollicitude, leur estime, leur touchante amitié, leur espoir, leur reconnoissance [...]. « ${ }^{67}$

Zwei autobiographische Skizzen Davids haben sich erhalten, die in dieser Hinsicht höchst aufschlussreich sind. In der ersten, sehr knappen, vom April $1793^{68}$ deutet sich bereits die Tendenz einer autonomen, da vaterlosen Selbstdefinition an, die dann nach 1808 in einem längeren, unvollendet gebliebenen Selbstzeugnis noch stärker akzentuiert wird und die bereits im Selbstporträt von 1794 anklang, in dem David sich als in der Haft Vereinzelter, Vereinsamter, aus allen familiären und sonstigen sozialen Bindungen Ausgestoßener dargestellt hatte. ${ }^{69}$ Das Ich, das in diesen Texten sein self-fashioning betreibt, definiert sich in seiner Lebensrolle einerseits über seine eigenen Lehrer, andererseits über die Schüler, die es selbst als Lehrer hervorgebracht hat. Als Ausgangspunkt für seine Künstlerkarriere im frühen Alter von zehn Jahren, unmittelbar nach dem Tod seines Vaters, wählt David das Orakel eines seiner Lehrer, der ihn im Lateinunterricht beim heimlichen Zeichnen ertappt und prognostiziert habe, "qu'il sera meilleur peintre qu'orateur «. ${ }^{70}$ In einer Inversion des von Benvenuto Cellini geprägten kunsttheoretischen Topos, dass die Kunstwerke die schönsten Kinder des Künstlers seien, heißt es dann: "Il n'a jamais obtenu aucune pension ni place à l'Académie. Ils n'ont cessé de lui faire injustice sur injustice mais ses élèves le vengeront car il les considère comme son meilleur ouvrage. ${ }^{71}$ David spricht hier von sich in der dritten Person, da sein Lebenslauf von Jean-Joseph Sue am 5. Mai 1793 während einer Sitzung des Lycée des Arts verlesen wurde. ${ }^{72}$

Davids privates Atelier, ${ }^{73}$ das meistfrequentierte seiner Zeit, in dem die exklusiv seinem Einfluss ausgesetzte Schülerschar zum `Meisterwerkı geformt wurde, avancierte zur Gegeninstitution der Académie royale de peinture et de sculpture, für deren Abschaffung $1793 \mathrm{Da}$ vid sich in mehreren Hetzreden engagiert hatte. Im Gegensatz zu dem an der Akademie produzierten Mittelmaß sollte sein Atelier geradezu eine `Exzellenzinitiative` darstellen: Tatsächlich räumten die David-Schüler schon in den 1780erJahren, aber dann auch in der Revolutionszeit, reihenweise die Rompreise ab, ihre Werke füllten die Salons. David fühlte sich für seine Schüler wie ein Vater für seine Kinder verantwortlich: Während seiner Haftzeit 1794 bangte er um das Wohl seiner Schule, die durch den gewaltsamen Entzug ihres Lehrers gewissermaßen kopf-, weil führungslos geworden sei. ${ }^{74} \mathrm{Die}$ unerhörte Tatsache, dass ihm, dem zu Unrecht angeklagten Lehrer, ausgerechnet das Atelier seines zum Militärdienst eingezogenen Schülers Jean-Mathieu Léger als Gefängniszelle zugesprochen wurde, musste David zum Zeichen dafür herhalten, dass die Welt aus den Fugen geraten war. Die natürlichen $\gg$ Familienverhältnisse innerhalb der Schule erschienen in ungehöriger Weise invertiert, wie der David-Schüler Pierre-Maximilien Delafontaine in seiner Beschreibung des Haftantritts seines Lehrers berichtet: "Lorsque l'arrestation de David fut décrétée, c'est moi Delafontaine qui l'accompagnais avec un seul invalide ou gardien qu'on lui avait envoyé avec l'ordre de se rendre à l'ancien Hôtel des Fermes, rue de Grenelles St Honoré, alors maison d'arrêt [...]. Il fut frappé d'étonnement en voyant que cette pièce était un petit atelier, mais je lui dis aussitôt, que cette pièce était l'atelier d'un de ses élèves nommé Légé, qui était le fils de l'ancien concierge [...] et que son élève était aux armées, ১Quelle fatalité, me dit-il, me voilà en prison dans l'atelier d'un de mes élèves! ce que c'est qu'une révolution! « ${ }^{75}$

Der homosoziale Verband seiner Schule ${ }^{76}$ ist in der Darstellung Davids nicht wie der der Académiciens einem zwanghaft-militanten Korpsgeist unterworfen, er stellt vielmehr einen Loyalitäts- und Freundschaftsbund dar, dem die Schüler aus freien Stücken aufgrund ästheti- 
scher Wahlverwandtschaft beitreten, um sich dann freiwillig dem künstlerischen Credo des väterlichen Freundes und Lehrers unterzuordnen. ${ }^{77}$ Im Dankesbrief an seine Schüler, die sich beim Nationalkonvent für ihren inhaftierten Lehrer zu verwenden versucht hatten, schreibt David in diesem Sinne Anfang Dezember 1794: "On rencontre donc aussi des jouissances dans le malheur, et certes j'en ai éprouvé depuis quatre mois, d'une nature à ne s'effacer jamais de ma mémoire [...]. Vous venez, mes bons amis, de m'en donner une preuve bien sensible; vos noms qui m'étaient déjà bien chers, maintenant sont pour jamais identifiés au bonheur de mon existence. ${ }^{78}$

Der patriarchalisch-hierarchisierten Struktur der Akademie wird hier die homosoziale Strukturierung freundschaftlich-brüderlicher Gleichberechtigung entgegengestellt. Auch wird man in die David-Schule nicht in einem biologischen Automatismus wie in eine Familie hineingeboren, sondern geht ein selbstgewähltes Abhängigkeitsverhältnis ein: Mittels der »instruction« wird der Schüler in die moralische Pflicht genommen, sich dem Freundschafts- und Treueversprechen seitens des Lehrers würdig zu erweisen, indem er dessen ästhetische Ideale teilt und perpetuiert. Diese alternative Form der Vergemeinschaftung im Männerbund ist strukturhomolog mit den gemalten Schwurszenen Davids: dem Schwur, den die Horatierbrüder ihrem Vater leisten und auch der Dritte Stand im Ballhaus seinem Vater Staat. Das von David propagierte neue genealogische Modell ist zugleich eine raffinierte Strategie des vater-äquivalenten Lehrers, die Verantwortung für die eigenen künstlerischen wie politischen Überzeugungen an die nächste Generation zu delegieren, indem er sie zu ewigen Erbwaltern über seinen eigenen Tod hinaus einsetzt. Nicht von ungefähr schenkte er Isabey sein selbstlegitimistisches Selbstporträt zu einem unbekannten Zeitpunkt nach seiner endgültigen Entlassung aus der zweiten Haft von Mai bis Oktober im Collège des Quatre-Nations, weil er es in den Händen seines Schülers am besten und zukunftsträchtigsten aufgehoben sah. Auch sein früheres, hier nicht behandeltes Selbstporträt von 1791 übergab David 1809 einem Schüler, nämlich François Gérard, aus dessen Nachlass es der schon erwähnte Delafontaine erwarb. ${ }^{79}$ Schließlich sind seine insistierenden Briefe an den Erbwalter seines Ateliers, Antoine-Jean Gros, aus dem Brüsseler Exil von dem gleichen Impetus geprägt. ${ }^{80}$

Nach der Rückkehr in sein Atelier Ende 1795 sah sich David immer wieder mit Fraktionenbildungen in seiner Schülerschar konfrontiert. Seine eigene Rolle als Revolutionspropagandist wandelte sich radikal zu der eines modéré, der schließlich zum Hofkünstler Napoleons avancieren sollte. Seine Ablehnung des Amtes eines peintre $d u$ gouvernement war weniger auf seine distanzierte Haltung dem Ersten Konsul gegenüber zurückzuführen als auf die in Davids Augen nicht hinreichenden Befugnisse, die mit dem Posten verbunden waren. ${ }^{81}$ Im Prozess gegen seinen Schüler François Topino-Lebrun 1800/1801, der am 30. Januar 1801 guillotiniert wurde, war David wenig hilfreich, da in seinen Verteidigungsbemühungen und den damit verbundenen politischen Stellungnahmen eher zurückhaltend. ${ }^{82}$ Doch auch die Schüler standen nach dem 9. Thermidor nicht mehr geschlossen hinter ihrem Lehrer: Der im Revolutionstribunal engagierte Gérard, der dann während der bourbonischen Restauration erneut Karriere machte, distanzierte sich von seinem Protektor in den Zeiten der Revolution. Anne-Louis Girodet hatte sich bereits 1789 mit seinem Weggang nach Italien von seinem Lehrer emanzipiert, nach seiner Rückkehr nach Frankreich 1795 wollte sich das frühere enge Verhältnis zu David nicht mehr so recht einstellen, vielmehr wurden die beiden zu Rivalen. Auch die Dissidentengruppe der sogenannten Barbus oder Primitifs um Maurice Quay zeigte deutliche Autonomisierungsbestrebungen: Sie lehnten den Imperativ gesellschaftspolitischen Engagements 
seit etwa 1797 strikt ab, proklamierten eine radikal-primitivistische Ästhetik und wurden dann auch folgerichtig vom Lehrer-Vater verstoßen, indem dieser sie um 1801 aus seinem Atelier verbannte. ${ }^{83}$

\section{Vaterlose Autonomie}

David betont in seiner autobiographischen Selbstinszenierung stets die autonome Verfassung seiner künstlerischen Selbstbegründung: Er hat in seiner Laufbahn als Künstler niemandem etwas zu verdanken als sich selbst - schon gar nicht seinem Vater, der bereits 1757 bei einem Duell starb, als David gerade einmal neun Jahre alt war, und dessen Erbgut ihn höchstens zum schnöden Kommerz prädestiniert hätte. Wenn überhaupt, so waren nur in seiner Familie mütterlicherseits künstlerische Anlagen vorhanden, allerdings keine, auf die David auch nur den geringsten Wert legte: ${ }^{84}$ Der von ihm politisch wie stilistisch verachtete Boudoir- und Frauenmaler sowie premier peintre $d u$ roi, François Boucher, war ein Cousin seiner Großmutter. Seinen Lehrer und Ersatzvater sucht David sich daher selbst und lässt sich bei seiner Wahl von keinerlei familiären, sondern allein von intrinsisch-ästhetischen Überzeugungen leiten. Die verkommene französische Schule zeichnete sich in seinen Augen in den 1770er-Jahren vor allem durch den galanteriewarenhaften "mauvais style« eines Jean-Honoré Fragonard ${ }^{85}$ oder eben eines Boucher aus. Der ins unheroische bürgerliche Wohnzimmer verlegte Klassizismus seines Lehrers Joseph-Marie Vien, den David als unterkühlt und seelenlos - "froid à la vérité ${ }^{86}$ - bezeichnet, stellte auch keine ernstzunehmende Alternative dar, sodass er hier niemanden finden konnte, der seinen hohen Kunstidealen genügte. So musste David notgedrungen nach Rom pilgern, um erst dort, dem schädlichen Einfluss der leichtfertigen école française »d'alors« entzogen, ${ }^{87}$ in kühner Überbrückung mehrerer Jahrhunderte, einen Lehrer zu finden, der ihn im antik-heroischen Stil unterweisen konnte: »Raphaël homme divin! c'est toi qui par degré m'éleva jusqu'à l'antique! C'est toi peintre sublime! c'est toi parmi les modernes qui est arrivé le plus près de ces inimitables modèles. C'est toi même, qui m'a fait apercevoir que l'antique était encore au-dessus de toi! C'est toi, peintre sensible et bienfaisant, qui plaças ma chaise devant les restes sublimes de l'antiquité. Ce sont tes doctes et gracieuses peintures qui m'en ont fait découvrir les beautés. Aussi après trois cents ans d'intervalle, pour prix de mon enthousiasme pour toi, daignes, ô Raphaël, me reconnaître encore pour un de tes élèves. ${ }^{88}$

Davids Selbstdefinition im Sinne der IchKonstitution erfolgt aber vor allem über die Schüler, die er selbst als Schulleiter hervorgebracht hat. In dem späten autobiographischen Fragment nimmt die Schilderung der Fortschritte der David-Schüler ein gutes Drittel des Gesamttextes ein; der viel zu früh verstorbene hierin und in seinem Talent Raffael vergleichbare - Lieblingsschüler Jean-Germain Drouais ${ }^{89}$ hängt mit abgöttischer Liebe an seinem Lehrer-Vater: »cette amitié réciproque, qui passa en une sorte d'idolâtrie de sa part. ${ }^{90}$ Allein Girodet macht sich selbst zum verstoßenen Sohn, indem er im künstlerischen Autonomiestreben zu weit geht und sich damit dem Vorwurf der Hybris aussetzt, den Lehrer mit unangemessenen Mitteln überbieten zu wollen und die klassizistische Kunstdoktrin (und damit seine Mitschüler und Brüder) verraten zu haben: »son défaut habituel était l'exagération«. Damit habe der Schüler ohne Not den Freundschaftsvertrag mit seinem "maître" aufgekündigt, der ihn leicht vor den ästhetischen Verirrungen eines "peintre libertin" hätte bewahren können, wenn Girodet sich nicht von seinem Umfeld auf Abwege und in Entgegensetzung zu seinem Lehrer hätte bringen lassen: »ils ne l'auraient pas éloigné de moi, j'aurais pu encore, en bon ami, lui dire ce que mon expérience me faisait découvrir dans 


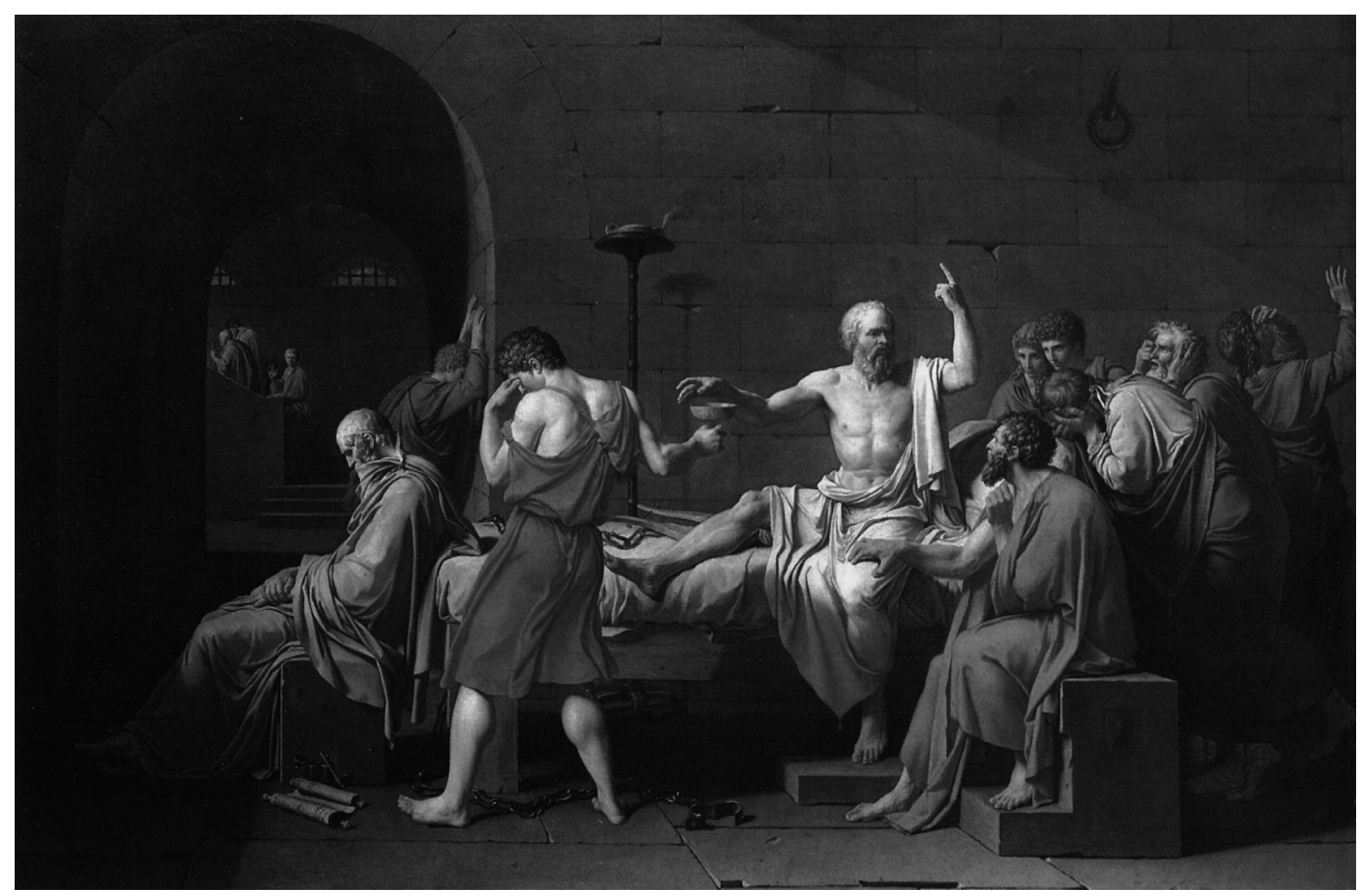

9 Jacques-Louis David, La mort de Socrate, 1787, Öl auf Leinwand, 129,5 × 196,2 cm. New York, The Metropolitan Museum of Art

sa manière [...]. Je lui aurais rappelé mes anciens reproches [...]. Je lui aurais représenté que le sujet de son tableau d'une scène de Déluge est d'un choix bizarre et que son grand talent [...] succomberait dans le choix d'un sujet pareil. Que si l'on ouvre la porte à de pareils sujets, il n'y a plus de raison de s'arrêter en si beau chemin. Adieu à la dignité de l'Art, adieu à ce beau idéal, seuls buts auxquels doit tendre le véritable peintre d'histoire, que ce genre tombe dans le ridicule qu'on applique aux mélodrames [...] «. ${ }^{91}$

Wie im Falle der neuen Identitätszuschreibung mithilfe des Selbstporträts in der Haftzeit dokumentieren nicht nur schriftliche Quellen dieses neugeschaffene genealogische Konzept Davids: Bereits 1786/1787 hatte er eine malerische Umsetzung einer solchen funktionierenden Lehrer-Schüler-Gemeinschaft präsentiert. In seiner autobiographischen Skizze vom Frühjahr 1793 bezeichnete er seinen Socrate buvant la ci- guë als sein künstlerisches Testament (Abb. 9).92 Der Praeceptor der attischen Philosophenschule ist in dem Moment dargestellt, in dem er den Schierlingsbecher ergreift; vielleicht war er das heroische Rollenmodell für David 1794 bei seinem Angebot an Robespierre, die »ciguë« mit ihm zu teilen. Doch im Gegensatz zum Maler zieht der Philosoph die letzte Konsequenz aus seinem Denken und Handeln. Selbst in dieser finalen Krisensituation ist er ganz Lehrer, er doziert bis zum allerletzten Moment. ${ }^{93}$ In der Salonkritik von 1787 des Grafen Stanisław Kostka Potocki, ${ }^{94}$ des von David in einem fulminanten Reiterbildnis porträtierten polnischen Winckelmann-Übersetzers, wird Sokrates zum ultimativen exemplum virtutis: »Socrate [...] lui seul [est] calme et tranquille, occupé d'une plus grande idée [...]. Voyez ce groupe d'amis, de disciples désolés, placés au chevet de son lit; ce que la nature, ce que le choix de l'antique nous offre de 
plus beau est réuni sur leurs figures; leur expression est vraie, variée et touchante. Par quel contraste puissant, par quel charme, Socrate, le difforme Socrate, écrase tant de beauté, de grace et de sentiment réunis! C'est le triomphe de la vertu, qu'un courage héroïque, qu'une âme divine élèvent au-dessus de tout."

Im Gegensatz zum und in bewusster Absetzung gegenüber dem als effeminiert kritisierten Rosa und Hellblau der Boudoirmalerei des Rokoko bedient David sich kräftiger Primärfarben, die in den Augen des Kritikers maskulin konnotiert sind und Potenz signalisieren: »Son coloris est mâle et vigoureux, sa touche ferme et hardie, sa manière large, son pinceau facile, bien que d'une exécution qui ne laisse rien à désirer $[\ldots] \ll{ }^{95}$ Davids Sokrates ist der antike Tugendheld par excellence, weil er ein als unabwendbar erkanntes Schicksal und den Urteilsspruch einer von ihm unhinterfragt anerkannten politischen Autorität, der Demokratie, stoisch ausführt, zugleich aber in diesem Akt der selbstgewählten Unterwerfung unter die einzig richtige Staatsform höchste Autonomie wahrt: Die Selbsttötung wird zum ultimativen Beweis eines geistesaristokratischen und bis zum Schluss selbstbestimmten Lebens, Sokrates avanciert damit zum Rollenmodell für den autonomen Künstler; die attische Demokratie wird zum Spiegelbild für Davids radikales Republikverständnis.

Doch der hier als erstrebenswert dargestellte Zustand stoischen Gleichmuts kann nur im Wissen darum, dass die eigenen Ideen und ästhetischen Ideale einen sicher überleben werden, erreicht werden. Das von David im Bild entworfene genealogische Modell eines harmonischen Lehrer-Schüler-Verhältnisses ist ein primär auf Zukunftssicherung gerichtetes: Es soll vor allem der Wahrung des ästhetischen Erbes des Lehrers dienen - das ja, allen Unschuldsbeteuerungen des Selbstporträts von 1794 zum Trotz, immer auch ein politisches Erbe war und ist. Formal bildet die als homosozialer Verband dargestellte
Schülerschar die dramatisch-emotionale Kontrastfolie, die den Stoizismus des `Vaters Sokrates noch authentischer hervortreten lässt. Der Lehrer kann seine Schüler trösten, indem er auf eine jenseits des irdischen Lebens befindliche Macht verweist. Strukturell nimmt er mit dem Hinweis, dass sein Reich nicht von dieser Welt ist, eine ähnliche Rolle wie Christus beim Letzten Abendmahl ein, die Philosophenschüler verweisen typologisch auf die Jüngerschar.

Gleichzeitig ist die Gruppe der Schüler nicht nur dadurch homogen strukturiert und als solidarische Gemeinschaft charakterisiert, dass es ausschließlich Männer sind, sondern auch dadurch, dass ihre sehr unterschiedlich modellierten Affekte sich ausbalancieren und der Gesamtgemütszustand der Gruppe letztlich doch den heroischen Stoizismus des Vaters/Lehrers spiegelt. Das weibliche Element (insbesondere die unrationalisierbare weibliche Emotionalität) verabschiedet sich in Form der im Hintergrund winkenden und über die Treppe abgehenden Xantippe und verschwindet damit endgültig aus Davids Männerkosmos. Die Extreme des Ausdrucks unter den Schülern gleichen sich in einer Art Mittelung der Gefühlswerte bis zum Nullzustand aller passions aus. ${ }^{96}$ Sie werden damit gleichermaßen zum Idealbild eines reibungslos funktionierenden republikanischen Staatswesens wie zu Kronzeugen des von David propagierten genealogischen Modells, in dem das Erbe des Lehrers von den Schülern angetreten wird: "Jeunesse intéressante et sensible, [je] te dirai souvent, garantis-toi de l'influence des froides passions, de la haine, de la jalousie, de l'envie [...]. Le génie ne respire que par les plus nobles sentimens, et les passions viles le tuent. Unissant ainsi les maximes de la morale aux leçons des beaux arts et aux préceptes de l'exemple, je guiderai tes pas dans le sentier difficile de la gloire, heureux de pouvoir bientôt les suivre sans distraction, et de laisser au bout de la carrière, des artistes plus dignes que moi de ses couronnes immortelles. ${ }^{47}$ 
Sokrates hat rechtzeitig für seine postmortale memoria gesorgt, indem er Schüler herangezogen hat, die seine philosophischen Ideale mit Sicherheit weitertragen werden - den Glauben an eine Welt der Ideen, an die Unsterblichkeit der Seele, oder, auf David übertragen, an eine zeitenüberdauernde Kunst. Hier, wie in vielen Gemälden Davids, ist eine die Botschaft des Bildes für die Nachwelt schriftlich dokumentierende Instanz ins Bild integriert: Platon, der Lieblingsschüler des Sokrates, übernimmt die Rolle des künftigen Historiographen. Am Fußende des Bettes, momentan noch von seiner Verzweiflung übermannt, dennoch aufrecht sitzend, wird er in Kürze seinen dokumentarischen Pflichten nachkommen, indem er die Dialoge niederschreiben wird, die die ganze Weisheit des Sokrates für alle Zeiten konservieren werden; das Weiß seines Gewandes und der antikische Faltenwurf machen ihn zu einer Art double seines Lehrers, dem er den stillen Schwur geleistet zu haben scheint, als sein immerwährendes Gedächtnis zu fungieren, das alle künftigen politischen Verwerfungen überdauern wird. Die Figur des Platon stellt eine Scharnierstelle in der Zeitstruktur des Bildes dar, die seiner historiographischen Aufgabe angemessen ist: Er sitzt mit dem Rücken zu Sokrates, nach links gewendet, und damit - den Konventionen der europäischen Leserichtung entsprechend - in der Zeitstruktur des Bildes der Vergangenheit zugewandt, der gegenüber er allerdings die Augen verschließt. Die Ohren jedoch hat er geöffnet, er lauscht auf die Botschaft für die Zukunft, die Sokrates in seinem Rücken ausspricht und die er tradieren wird - so wie David die republikanischen Ideale und seine Zukunftshoffnungen im Bild verewigen sollte. Die Signatur auf dem Steinkubus, auf dem Platon sitzt, macht den Geschichtsschreiber und Philosophen seinerseits zum double des Malers.
V. Der Republikaner auf verlorenem Posten:

\section{Leonidas an den Thermopylen}

Dass die republikanische unité de doctrine, die sich in Davids Festinszenierungen der Revolutionszeit so augenfällig abgebildet hatte, nach dem 18. Brumaire des Jahres VIII (1799), spätestens jedoch nach der Selbstermächtigung Napoleons zum Kaiser der Franzosen 1804 und seinen immer desaströser verlaufenden militärischen Expansionsbestrebungen unwiederbringlich zerbrochen ist ${ }^{98}$ und denjenigen, der weiter heroisch an ihr festhalten möchte, zu einem Helden auf verlorenem Posten macht, scheint die Botschaft des letzten hier zu analysierenden Beispiels zu sein: Léonidas aux Thermopyles. ${ }^{99}$ Dieses höchst merkwürdige Bild, ${ }^{100}$ begonnen 1799, fertiggestellt 1814 (Abb. 10), will wohl auch darauf hinweisen, dass das revolutionäre Ideal spartanischer Selbstzügelung und autonomer Selbstbestimmung im neuen nachrevolutionären politischen Kontext des imperialistischen Regimes, insbesondere seit dem Russlandfeldzug 1812 mit seinen über 500.000 Todesopfern, nicht mehr lebbar ist und man nur noch melancholisch darüber reflektieren kann, dass es ein vergangenes ist. ${ }^{101}$ David schreibt in der Ekphrase seines Bildes: "Léonidas, roi de Sparte, assis sur une roche au milieu de ses trois cents braves, médite, avec une sorte d'attendrissement, sur la mort prochaine et inévitable de ses amis. ${ }^{102}$ Es ist die inhaltliche Korrespondenz der Situationen, die David veranlasste, als Vorlage für die Haltung des Leonidas eine antike Ajax-Gemme (nach Winckelmanns Monumenti antichi inediti von 1767) zu wählen: ${ }^{103}$ Ajax steht hier unmittelbar vor seinem Selbstmord, weil er die Schmach nicht ertragen kann, im Kampf um die Waffen des Achill gegen Odysseus unterlegen zu sein und dann in seiner Raserei, von Athena verblendet, eine Widderherde statt des verhassten Gegners niedergemetzelt zu haben.

Wie Werner Busch für die von ihm sogenannte dritte Stufe der diagnostizierten Krise des His- 


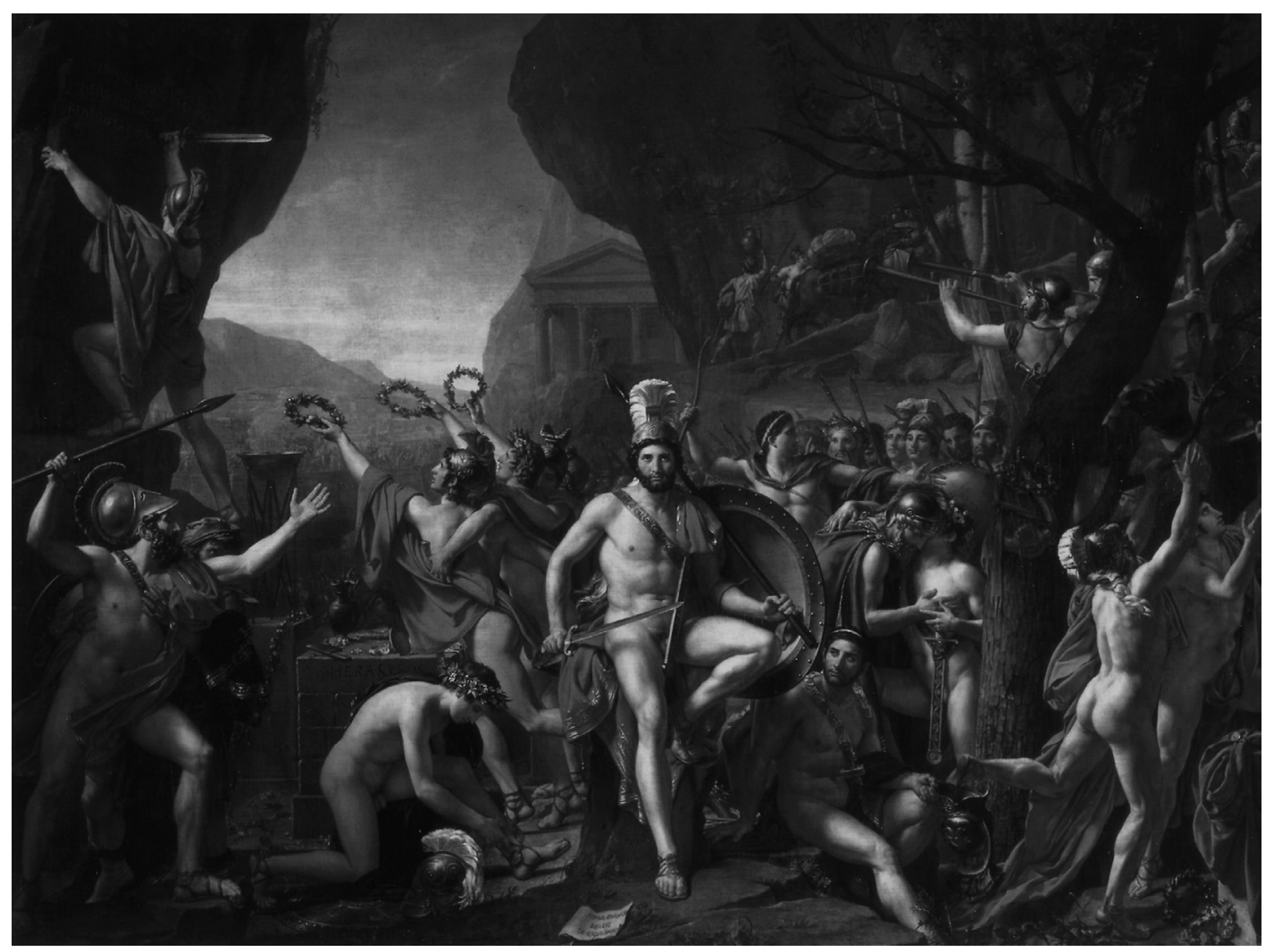

10 Jacques-Louis David, Léonidas aux Thermopyles, 1799-1814, Öl auf Leinwand, $395 \times 531$ cm. Paris, Musée du Louvre

torienbildes um 1800 festgestellt hat, gerät auch der Held selbst in die Krise, er wird handlungsunfähig, das Reflexionsmoment suspendiert die Aktion. ${ }^{104}$ Die Darstellung seines heroischen Agierens wird ersetzt durch die Meditation über die Konsequenzen der in der Vergangenheit liegenden Entscheidung (wie schon beim Brutus). Bisweilen tritt unmotivierter, blinder Aktionismus an die Stelle der Handlung - im Léonidas beispielsweise bei den vor dem Altar tänzelnden und Blumenkränze emporreißenden Kriegern links mit ihren rosigen Pobacken, die sich von Leonidas ab- und einem Schwur ultimativer gemeinschaftlicher Todesbereitschaft zuwenden, der so gar nicht zu ihrem leichtfertigen Gehabe passen will. ${ }^{105}$ Sie verkehren die körperliche Vereinigung der Horatierbrüder in ihr Gegenteil und invertieren, ja pervertieren sie damit. ${ }^{106}$ Die homoerotische Komponente effeminierter Männer klingt an verschiedenen Stellen des Bildes an; die
Abschiedsszene zwischen Vater und Sohn ${ }^{107}$ ist in der zeichnerischen Alternative von 1817 (Abb. 11) klar von männlich-männlichem Begehren geprägt; den eindeutig sexualisierten Kuss hatte David im Gemälde noch zur Abschiedsumarmung abgemildert. ${ }^{108}$ Das weibliche Element scheint hier von dem ausschließlich männlichen Personal mit abgedeckt zu werden. ${ }^{109}$

Auch die nach ihren im Baum aufgehängten Waffen springenden Jünglinge rechts sind durch ihr formales Vorbild, Giambolognas Merkur, in den Augen des Erzklassizisten David als manieristisch-überdreht disqualifiziert. ${ }^{110}$ Sämtliche Figuren im Bild weisen manierierte Längungen und Stauchungen auf, die den klassi(zisti)schen Figurenidealen des 18. Jahrhunderts zuwiderlaufen; ihre Haltungen sind gesucht, sie nehmen sinnentleerte Posen ein und drehen leerlaufende Pirouetten. Während die expression des passions im Socrate unter den Philosophenschülern noch 


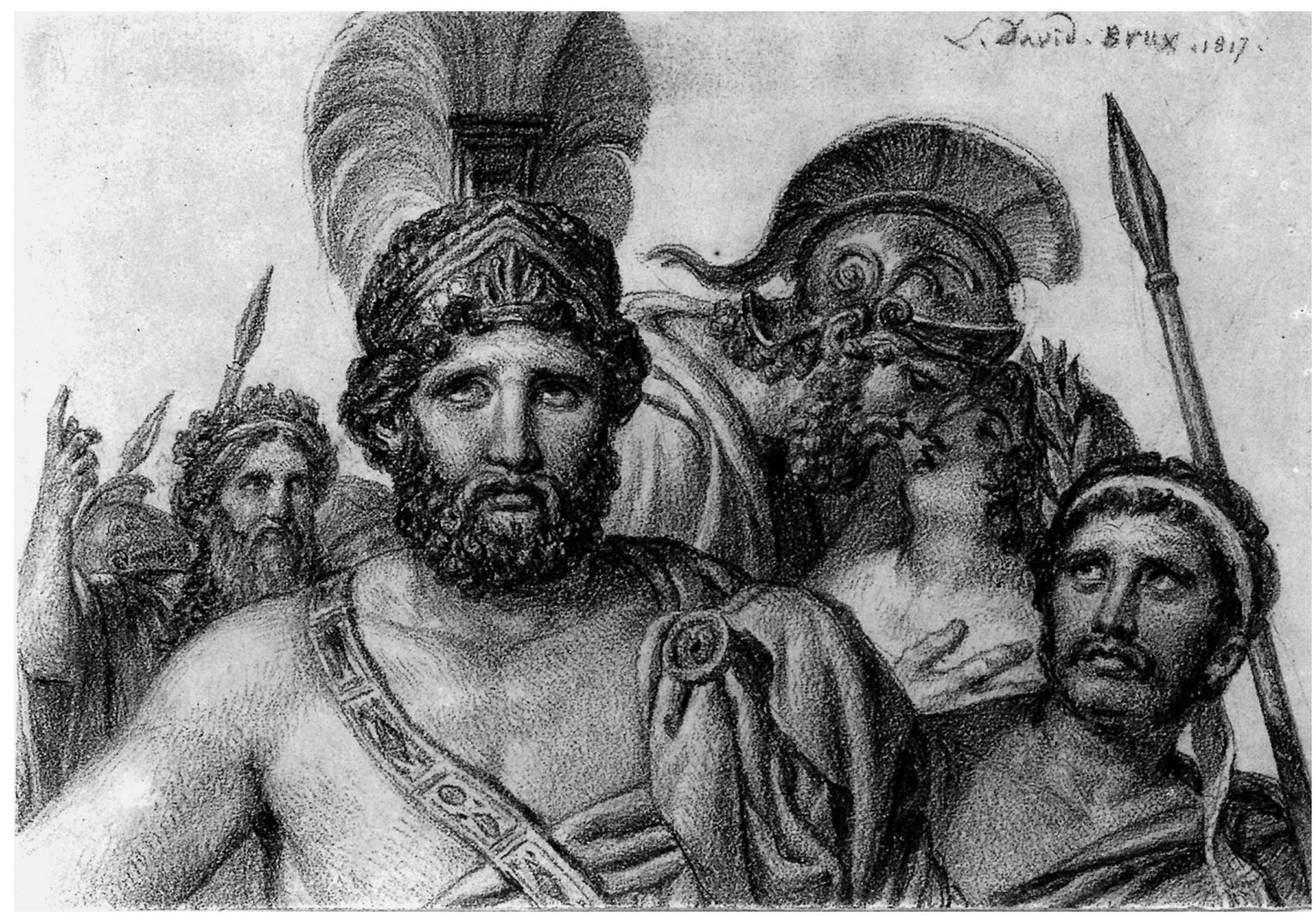

11 Jacques-Louis David, Alternative pour le Léonidas, 1817, schwarzer Bleistift. Privatsammlung

ausgeglichen und damit normästhetisch korrekt war, weshalb David selbst dieses Bild als "peutêtre son chef-d'œuvre d'expression «"111 bezeichnete, läuft hier alles aus dem Ruder. Ein unheroischeres und unspartanischeres Auftreten als der laszive Männertanz links, ein effeminierteres als das des Sandalenbinders im Vordergrund oder der libidinalen homoerotischen Szene im Hintergrund ist kaum denkbar: In diesem Umfeld ist kein Platz mehr für den Helden von Sparta und für die revolutionären Ideale Davids. Die blumenbekränzte Brüderbande links bringt ein sinnloses Opfer, denn weder Herkules, der Krieger, noch Aphrodite, die Göttin der Liebe und Prokreation, können zukünftig noch etwas für die Todgeweihten ausrichten, die sich ein letztes Mal in unfruchtbarer fraternité vereinen. ${ }^{112}$ Doch die Inkunabel von Sinnlosigkeit der hier dargestellten Einzelaktionen, die die geschlossene Handlung sprengen, ist der blinde
Alte links, der trotz seiner ihn kampfuntauglich machenden Invalidität (emblematisch verdichtet in seiner unprofessionellen Speerhaltung) darauf besteht, in verblendetem Eifer in die Schlacht zu ziehen - er kann ja die Übermacht des persischen Heeres nicht sehen.

Leonidas als die Personifikation des zum Scheitern verurteilten Ideals der Revolution kann die kompositorische Funktion, die anderen Figuren an sich zu binden und somit eine Führergestalt und Identifikationsfigur zu sein, in diesem Kontext nicht mehr erfüllen - er ist vollkommen allein, er tritt nicht in Interaktion mit den ihn Umgebenden, er ist im `Exil (wie David selbst nach 1816 in Brüssel, wohin er das Leonidas-Bild mitnahm). Das übrige Bildpersonal strebt, von seinen ungezügelt ausgelebten passions wild bewegt und getrieben, von ihm weg, an die Bildränder - eine kompositorische Entscheidung, die vor allem im Vergleich mit ei- 


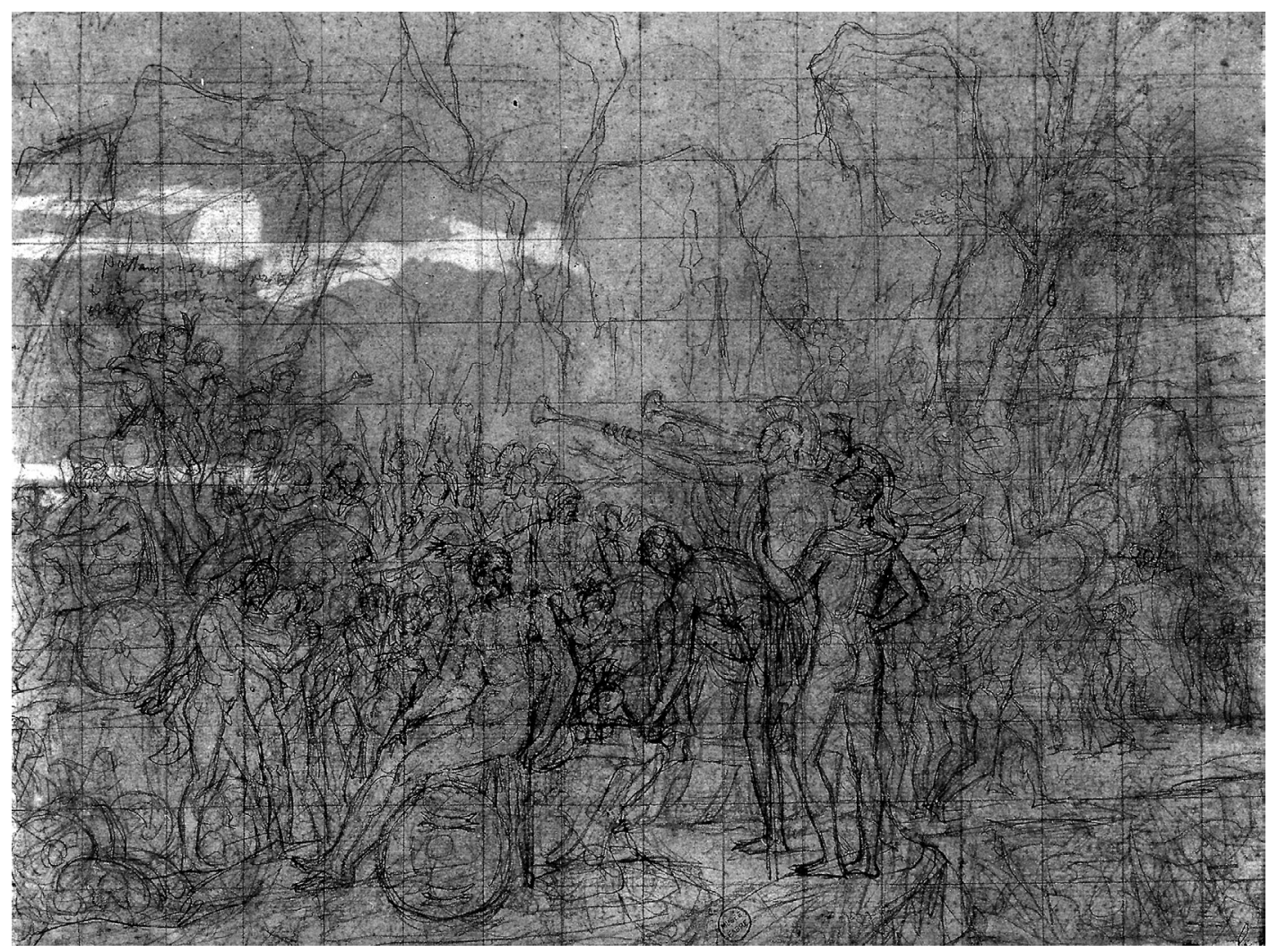

12 Jacques-Louis David, Première pensée pour Léonidas aux Thermopyles, um 1800, Bleimine, $32 \times 42 \mathrm{~cm}$. Montpellier, Musée Fabre

nem der ersten Entwürfe (auf der heute in Montpellier befindlichen Zeichnung) deutlich wird (Abb. 12). Die unité der Bildkomposition löst sich auf, ${ }^{113}$ die Solidargemeinschaft unverbrüchlicher fraternité existiert nicht mehr als unité de doctrine. Die Position des Leonidas markiert das seit dem Königsmord leere Zentrum, das durch den hier als pervertiert dargestellten Brüderbund nicht gefüllt werden kann. ${ }^{114} \mathrm{Nie}-$ mand hat mehr ein Auge für die Hauptfigur übrig. Der Blick des unterhalb von ihm Sitzenden, seines Schwagers Agis, wird durch den Schild abgewehrt, allein der Blinde schaut paradoxerweise in seine Richtung - und der dunkelhäutige Sklave, der diesen führt und der als Außenseiter eine ebenso marginalisierte Position innehat wie der gescheiterte Held im Bildzentrum. Im überdrehten Männerballett der Todgeweihten ist das beau idéal Davids als gescheitert dar- gestellt. Der Léonidas ist auf den ersten Blick ein resignatives Bild, das in der nachrevolutionären Zeit politisch »nicht mehr funktional « war, sondern den Patriotismus nur noch auf der Leinwand aufrecht erhalten konnte, wie David laut Delécluze nach dem 18. Brumaire selbst betont haben soll.115

Aber den moralischen Sieg trägt dieser Märtyrer für die richtige spartanisch-republikanische Sache dann doch davon: ${ }^{116}$ Leonidas wahrt seine Autonomie im Bild dadurch, dass er - wie Brutus - eine einsame Entscheidung getroffen hat, die er - wie Sokrates - mit tödlicher Konsequenz realisieren und die damit zu seiner letzten wird. Nicht von ungefähr ist er die einzige Figur, die unüberschnitten Platz im Bild hat; er verharrt, gänzlich isoliert, in stoischer Ruhe und durch seine frontale Stellung aus dem Getümmel separiert. ${ }^{117}$ Dorothy Johnson hat zu 
Recht auf die Differenzierung der expressions des passions in den Jahren nach 1800 hingewiesen $^{118}$ und den Gesichtsausdruck des Leonidas, der von den Zeitgenossen bewundernd als "sublime " beschrieben wurde, ${ }^{119}$ als ein Beispiel für diese subtileren Modi der Darstellung von Innerlichkeit, von Gefühlen der Zerrissenheit des nachrevolutionären, ‘modernen Helden benannt, ${ }^{120}$ wie sie bereits anhand der Analyse des Selbstporträts von 1794 aufgezeigt werden konnten. Leonidas wird in seiner passionslosen Gegenwartsdiagnostik zu einem Rollenmodell für radikal-moderne, nur noch auf sich selbst gestellte Subjektivität. An der eigentlichen Bilderzählung nimmt er schon nicht mehr teil, sein Blick, der wie im Brutus den Reflexionsraum für den Betrachter eröffnet, ist aus dem Bildraum hinaus nach oben und in die Zukunft gerichtet, in der allein noch Hoffnung liegt. ${ }^{121}$

Der Brief zu seinen Füßen, mit dem Leonidas zwei seiner jugendlichen Mitstreiter unter dem Vorwand einer geheimen Mission nach Sparta schicken und sie damit vor dem sicheren Tod bewahren wollte, ist Makulatur, da er der Vergangenheit angehört. Das einzige, was die im Bild gegebene Szene überdauern wird, ist auch hier die historische Dokumentation des Ereignisses als zukünftige Vergangenheit, seine von dem Spartaner links mit dem Schwertknauf in den moosbewachsenen Fels gemeißelte memoria. ${ }^{122}$ Der Historiograph ist der eigentliche Held im Bild, und er wird einmal mehr zum double des Malers, der ihn in seinem Gemälde einer künftigen Generation überliefert, welche vielleicht dann doch irgendwann in der Lage sein wird, die Lehren der Geschichte im wahrhaft revolutionären Sinne in die politische Realität umzusetzen.

Davids Léonidas reflektiert damit wie eigentlich sämtliche seiner Gemälde den politischen Kontext seiner Entstehungszeit. Er ist der Versuch, die nachrevolutionäre Krise und den für David nicht zu vollziehenden Übergang in eine restaurative konstitutionelle Monarchie mit for-

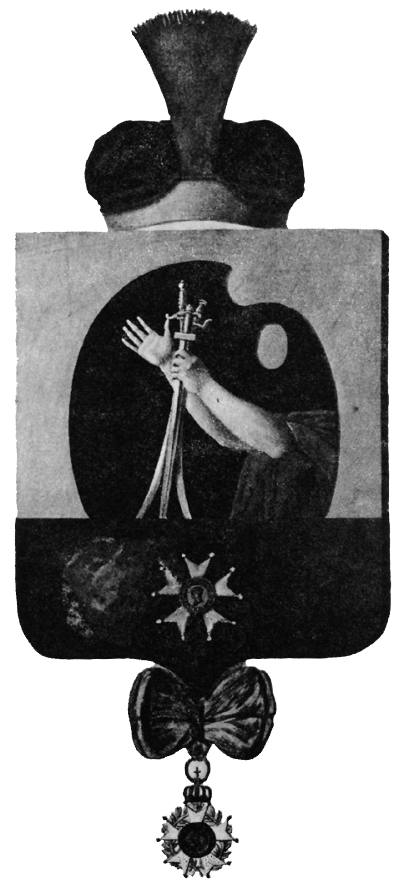

13 Les armes de David, peintes par lui-même. Privatsammlung

malen Mitteln darzustellen. ${ }^{123}$ Der Léonidas ist ein Bild »that is all about the fragility of a legacy, the problem of an inheritance, and the prospects of its persistence ${ }^{124}$ David historisiert hier wie in seinem Selbstporträt seine eigene revolutionäre Vergangenheit, die dadurch, dass sie als Geschichte im Spiegel der Historie erzählt wird, im Rückblick als bild- und geschichtswürdig legitimiert erscheint.

Dass für David die Nibelungentreue in der politischen wie künstlerischen Erbwaltung auch als premier peintre des Parvenus Napoleon Bonaparte (ein Titel, der ihm 1804 verliehen worden war) das höchste Gut blieb, dokumentiert nicht nur der Léonidas, sondern auch sein selbstentworfenes Wappen aus dem Jahr $1808,{ }^{125}$ vier Jahre, nachdem der ehemalige Jakobiner zum chevalier de l'Empire ernannt worden war: Auf diesem Phantasiewappen (Abb. 13) wird sein erfolgreichstes Frühwerk, der Schwur der Horatier, noch einmal zitathaft in einem sprechenden Detail aufgerufen. Die Palette des Malers ist jetzt in einen Schutzschild verwan- 
delt, der noch einmal ostentativ das künstlerische wie politische Credo des Republikaners David vorträgt. Im unteren Drittel zeigt das Wappen das Großkreuz der Légion d'honneur und den auf ihm inschriftlich wie auch in einer Porträtbüste all'antica präsenten »Empereur Napoléon«. Die emblematische Repräsentation von Davids überaus produktiver Phase als Hofkünstler des Kaisers ${ }^{126}$ greift damit in die revolutionäre Vorgeschichte ein und überdeckt sie teilweise. Der obere Teil aber enthält das Legat des Malers an die Zukunft, das sich auf die Gründungsphase seiner Kunst bezieht: So wie der Vater der Horatierbrüder die Schwerter an seine

* Wolfgang Braungart, Johannes Grave, Klaus Heinrich Kohrs, Sigrid Ruby, Bernd Mohnhaupt, Semjon Aron Dreiling, Wolfgang Hardtwig, Regina Wenninger und einem der anonymen Leser im Rahmen des peer reviewing danke ich für konstruktive Hinweise und anregende Diskussionen.

1 Hierzu Philippe Bordes, Le Robespierrisme de JacquesLouis David, in: Yearbook of European Studies 9, 1996 (Special Issue: Robespierre - Figure-Réputation, hg. von Annie Jourdan), 121 - 141; ders., »Brissotin enragé, ennemi de Robespierre«: David, conventionnel et terroriste, in: Régis Michel (Hg.), David contre David. Actes du colloque au musée du Louvre, Bd. 1, Paris 1993, 319 - 347, gegen den eher legitimistischen Ansatz bei David L. Dowd, Pageant-Master of the Republic. J.-L. David and the French Revolution, Lincoln, NE 1948; Régis Michel und Marie-Catherine Sahut, David, l'art et le politique, Paris 1988. Vgl. auch T. J. Clark, Painting in the Year Two, in: Representations 47, 1994 (Special Issue: National Cultures before Nationalism), 13-63.

2 Mona Ozouf, La fête révolutionnaire 1789-1799, Paris 1987; Jean Ehrard und Paul Viallaneix (Hg.), Les fêtes de la Révolution. Actes du colloque à Clermont-Ferrand (juin 1974), Paris 1977; vgl. auch Thomas Crow, Painters and Public Life in Eighteenth-Century Paris, New Haven/London 1985.

3 Hierzu Michel Eude, Le Comité de sûreté générale en 1793 - 1794, in: Annales historiques de la Révolution française 261, 1985, 295 -306; David L. Dowd, Jacques-Louis David, Artist Member of the Committee of General Security, in: American Historical Review 57, 1952, $871-892$.

4 Vgl. u. a. Joseph Clarke, Commemoration of the Death in Revolutionary France. Revolution and Remembrance, 1789-1799, Cambridge 2007/22011.
Söhne weitergegeben hatte, so reicht er seine Palette an die nächste Künstlergeneration weiter. Doch eine entscheidende Abweichung vom Serment des Horaces ist zu konstatieren: Die Hände der Söhne sind aus dem Bildausschnitt eliminiert - dem, der hier die Ideale hochhält, sekundiert offenbar niemand mehr aus der nächsten, in Fraktionen zerstrittenen Generation. Die Frage, wer jetzt noch die Schwerter zum unerbittlichen Kampf für die Republik ergreifen mag, bleibt in den Jahren nach 1812 unbeantwortet. Der unverbesserliche Republikaner David malt sie sich nur noch als trotziges Selbstbekenntnis auf seiner Palette aus.

5 Vgl. Antoine Schnapper, A propos de David et des martyrs de la Révolution, in: Michel Vovelle (Hg.), Les Images de la Révolution française. Actes du colloque, Paris 1988, 109-117; Jacques-Louis David, 1748 - 1825 (Ausst.-Kat. Paris, Musée du Louvre), hg. von Antoine Schnapper, Paris 1989, Kat.-Nr. 123, 124. Philippe Bordes bringt den Opernvorhang mit dem Sturz Dantons und Davids Beteiligung hieran in Verbindung; Bordes 1993 (wie Anm. 1), 334-338.

6 Ebenda, 340 .

7 Vgl. die ausführliche Beschreibung des Triomphe de la liberté et du peuple bei Alexandre Lenoir, David. Souvenirs historiques, in: Journal de l'Institut historique 2, 1835, 1-13, hier 7f.; vgl. auch Antoine de Baecque, Le corps meurtri de la Révolution. Le discours politique et les blessures des martyrs (1792 - 1794), in: Annales historiques de la Révolution française 287, 1987, 17 - 41.

$8 \mathrm{Vgl}$. Antoine de Baecque, Le corps de l'histoire. Métaphore et politique (1770 - 1800), Paris 1993.

9 Hierzu und zum Folgenden: Christine Tauber, Nachwort: Bauen auf der tabula rasa, in: ArmandGuy Kersaint, Abhandlung über die öffentlichen Baudenkmäler. Paris 1791/92, hg. von Christine Tauber, Heidelberg 2010, 175 -284, v. a. $208-219$.

10 Philippe Bordes, Le Serment du Jeu de Paume de J.-L. David, Paris 1983.

11 Hierzu u. a. Thomas Crow, The Oath of the Horatii in 1785: Painting and Pre-Revolutionary Radicalism in France, in: Art History 1, 1978, 424-471.

12 Hans Körner, Auf der Suche nach der »wahren Einheit«. Ganzheitsvorstellungen in der französischen Malerei und Kunstliteratur vom mittleren 17. bis zum mittleren 19. Jahrhundert, München 1988, 156, spricht zutreffend von der »Utopie des rechten Winkels«. 
13 Christine Tauber, Bilderstürme der Französischen Revolution. Die Vandalismusberichte des Abbé Grégoire, Freiburg i. Br. 2009, 236-243.

14 Hierzu Lynn Hunt, The Family Romance of the French Revolution, London 1992, Chapter 1: "The Family Model of Politics«, $1-16$, und Chapter 2: »The Rise and Fall of the Good Father«, 17 -52. Vgl. auch Philippe Bordes, Jacques-Louis David. Empire to Exile (Ausst.-Kat. Los Angeles, J. Paul Getty Museum und Williamstown, Mass., Sterling and Francine Clark Art Institute), New Haven/London 2005, 12, der Davids Brutus zutreffend als "an unnatural father« bezeichnet.

15 Vgl. hierzu und zum Folgenden die überzeugende Analyse der »Funktion der kompositionellen Ordnung für die intendierte Bildaussage im Schwur der Horatier und im Brutus bei Körner 1988 (wie Anm. 12), v. a. 131 -160, hier 135. Vgl. ebenda, 137: »Die augenscheinliche Gewaltsamkeit, mit der die männlichen Figuren in dieses ordnende Gefüge eingepaßt sind, hebt die Radikalität der Gesinnung, die Gewaltsamkeit der Forderung, alles Persönliche dem überpersönlichen Gesetz zu opfern, ins Sichtbare." Vgl. auch die Analyse der Horatier bei Robert Rosenblum, Transformations in Late Eighteenth Century Art, Princeton 1967, 67-73.

16 Hierzu Hunt 1992 (wie Anm. 14), v. a. Chapter 3: »The Band of Brothers«; vgl. auch Marcel David, Fraternité et Révolution française, 1789-1799, Paris 1987.

17 Auch ohne eine explizite gender-Theorie lassen sich Davids Bilder auf diese Darstellungen von Geschlechterdifferenzen hin mit Gewinn analysieren; vgl. Norman Bryson, David et le gender, in: Michel 1993 (wie Anm. 1), 703 - 724; ders., Tradition and Desire. From David to Delacroix, Cambridge 1984; Abigail Solomon-Godeau, Male Trouble. A Crisis in Representation, London 1997; Mechthild Fend, Der Androgyn in der französischen Kunst und Kunsttheorie 1750-1830, Berlin 2003.

18 Vgl. Albrecht Koschorke, Die Heilige Familie und ihre Folgen. Ein Versuch, Frankfurt a. M. 2000. David verarbeitet in der Frauen- und Kindergruppe seiner Horatier weitere Elemente aus der christlichen Ikonographie wie die Anna selbdritt, die Schutzmantelmadonna und die durch die Hl. Elisabeth und den Johannesknaben zur Fünferkonstellation erweiterte Heilige Familie, der erneut Josef abhanden gekommen ist.

19 Hierzu Robert L. Herbert, David, Voltaire, Brutus and the French Revolution: an Essay in Art and Politics, London 1972; Thomas Puttfarken, David's Brutus and Theories of Pictorial Unity in France, in: Art History 4, 1981, 291 - 304; Philippe Bordes, Les mânes de Brutus: Le roman noir de la vertu républicaine, in: Histoire, images, imaginaires (fin $X V^{\mathrm{e}}$ siècle-début $X X^{\mathrm{e}}$ siècle). Actes du colloque international des 21-22-23 mars 1996 tenu à l'Université du Maine, hg. von Michèle Ménard und Annie Duprat, Le Mans 1998, 365 -379; La mort de Brutus de Pierre-Narcisse Guérin (Ausst.-Kat. Vizille, Musée de la Révolution française), hg. von Philippe Bordes, Vizille 1996.

20 Hierzu Stefan Germer und Hubertus Kohle, From the Theatrical to the Aesthetic Hero: On the Privatization of the Idea of Virtue in David's Brutus and Sabines, in: Art History 9, 1986, 168 - 184.

21 Vgl. Körner 1988 (wie Anm. 12), 150.

22 Vgl. David in seinem Brief an seinen Schüler Wicar vom 14.6.1789, also einen Monat vor dem Sturm auf die Bastille: »Donc je voulais vous dire que je fais un tableau de ma pure invention. C'est Brutus, homme et père, qui s'est privé de ses enfants, et qui, rentré dans ses foyers, on lui rapporte ses deux fils pour leur donner la sépulture. Il est distrait de son chagrin, au pied de la statue de Rome, par les cris de sa femme, la peur et l'évanouissement de la plus grande fille«; David und Guy Wildenstein, Documents complémentaires au catalogue complet de Louis David, Paris 1973, Nr. 207, 28. Laut Rosenblum verwandelt David "the women of the family into a group of hysterical bacchantes« (Rosenblum 1967 [wie Anm. 15], 77). David bittet Wicar, der in Rom noch direkten $\mathrm{Zu}$ griff auf die antiken Vorbilder hat, im gleichen Brief, dort Bacchantinnenköpfe von antiken Sarkophagen abzuzeichnen, die als Vorbilder für die Frauenköpfe im Brutus dienen sollen: »Vous me feriez un plaisir de me croquer sur ce... tête pour la coiffure et dans la position que je vais vous marquer. Il me semble que vous trouveriez plutôt cela dans les Bacchanales. On y voit souvent de ces Bacchantes avec ces espèces d'attitudes".

23 Vgl. Oskar Bätschmann, Das Historienbild als "Tableau" des Konflikts. Jacques-Louis Davids "Brutus" von 1789, in: Wiener Jahrbuch für Kunstgeschichte 39, 1986, 145-162, hier 160: »Wie im Bürgerhaus des 18. Jahrhunderts geht in Davids römischem Privathaus die Trennungslinie zwischen öffentlich und privat mitten durch das Gebäude."

24 Vgl. Norman Bryson, Looking at the Overlooked. Four Essays on Still Life Painting, London 1990, 156 f.

25 Damit soll keinesfalls die in der älteren David-Literatur verbreitete, methodisch absurde Forschungsmeinung vertreten werden, der Maler habe in den Horatiern und im Brutus (mithin in diesem Bild mit königlichem Auftrag, dessen Inhalt durchaus auch mit einer monarchischen Ideologie vereinbar war) die Revolution gleichsam seismographisch vorausgeahnt; vgl. David Carrier, Was David a Revolutionary Before the Revolution? Recent Political Readings of "The Oath of the Horatii« and »The Lictors Returning to Brutus the Bodies of his Sons«, in: Dor- 
othy Johnson (Hg.), Jacques-Louis David: New Perspectives, Newark, DEL 2006, 108 -118; vgl. auch Carol Duncan, Fallen Fathers: Images of Authority in Pre-Revolutionary French Art, in: Art History 4, 1981, H. 2, 186-202, hier 194; Hunt 1992 (wie Anm. 14), $21-26$.

26 Vgl. die luzide Analyse von Bronisław Baczko, Comment sortir de la terreur. Thermidor et la Révolution, Paris 1989.

27 Réimpression de l'Ancien Moniteur (Mai 1789 Novembre 1799), Bd. 21, Paris 1841, 367f.: »Ce n'était pas pour venir faire l'accueil à Robespierre«, versucht David sich am 13. Thermidor zu entlasten, "que je descendis de son côté, c'était pour monter à la tribune et demander que l'heure de la fête du 10 fût avancée. Je n'ai pas embrassé Robespierre, je ne l'ai même pas touché, car il repoussait tout le monde. Il est vrai que, lorsque Couthon lui parla de l'envoi de son discours aux communes, je dis qu'il pourrait semer le trouble dans toute la République. Robespierre s'écria alors qu'il ne lui restait plus qu'à boire la ciguë; je lui dis: Je la boirais avec toi.« Vgl. auch Wildenstein 1973 (wie Anm. 22), Nr. 1117; 1118; 1119, 114.

28 Nur im engsten privaten Kreis soll David sich seinen Söhnen gegenüber nach dem 9. Thermidor noch positiv über Robespierre geäußert haben. Vgl. Wildenstein 1973 (wie Anm. 22), Nr. 1124, 113: »On vous dira que Robespierre était un scélérat; on vous le peindra sous les couleurs les plus odieuses, n'en croyez rien. Il viendra un jour où l'histoire lui rendra une éclatante justice«. Vgl. Satish Padiyar, Last Words: David's Mars Disarmed by Venus and the Graces (1824), in: RIHA Journal 0023, 1. Juni 2011, URL: http://www.riha-journal.org/articles/2011/ 2011-apr-jun/padiyar-last-words (letzter Zugriff am 17. Juli 2016), 1-45, hier 6-14.

29 Wildenstein 1973 (wie Anm. 22), Nr. 1120; 1121, 114.

30 Réimpression de l'Ancien Moniteur 1841 (wie Anm. 27), 368.

31 David an Boissy d'Anglas am 16.11.1794; Wildenstein 1973 (wie Anm. 22), Nr. 1145, 116; vgl. auch ebenda, Nr. 1138, 114: »on ne peut me reprocher qu'une exaltation d'idées qui m'a fait illusion sur le caractère d'un homme que beaucoup de mes collègues plus éclairés que moi regardaient comme la boussole du patriotisme«. Etienne Delécluze glaubte seinem Lehrer David diese Schutzbehauptung und kolportiert sie wörtlich, wenn er von den »incroyables illusions qu'il entretenait dans son imagination exaltée« berichtet. Bei der verklärenden Darstellung des David-Schülers Delécluze in David, son école et son temps, Paris 1855 (Neuaufl. Paris 1983, 169) ist höchste quellenkritische Vorsicht geboten, da diese retrospektive Panegyrik über das David-Atelier und die Werke seines verehrten, 1825 verstorbenen Lehrers erst über 50 Jahre ex post publiziert wurde und vor allem dazu diente, `Etiennes« Sonderstellung als Lieblingsschüler Davids zu behaupten.

32 Vgl. Ewa Lajer-Burcharth, Les œuvres de David en prison: art engagé après Thermidor, in: Revue $d u$ Louvre 39, 1989, 310 - 321, hier 313; Gerrit Walczak, Bürgerkünstler. Künstler, Staat und Öffentlichkeit im Paris der Aufklärung und Revolution, Berlin/ München 2015, XII, spricht zutreffend vom »Klischee berufsbedingter Unzurechnungsfähigkeit «.

33 Wildenstein 1973 (wie Anm.22), Nr. 1198, 131f.: »Exempt de toute espèce d'ambition et seulement passionné pour la gloire que donnent les beaux arts, je n'ai accepté des fonctions publiques que dans la vue de les servir, et d'assurer leur prospérité [...]. Qu'on examine ma conduite pendant tout le tems que j'ai été associé aux douloureuses obligations de ce comité [de sûreté générale], on y reconnoîtra l'inquiétude d'un homme transporté hors de sa sphère et entraîné par le tourbillon révolutionnaire dans des fonctions étrangères à son caractère, à ses connoissances, à ses principes, à son cœur.«

34 Vgl. David A. Wisner, Du Nouveau sur la première arrestation de David, in: Annales historiques de la Révolution française 289, 1992, 431 - 443.

35 Die bislang überzeugendsten Überlegungen zum Selbstporträt von 1794 haben T. J. Clark und Ewa Lajer-Burcharth vorgelegt: T. J. Clark, Gross David with the Swoln Cheek: An Essay in Self-Portraiture, in: Michael Roth (Hg.), Rediscovering History. Culture, Politics and the Psyche, Stanford 1994, 243 - 307 und 482-493; Lajer-Burchhardt 1989 (wie Anm. 32); ähnlich (unter Einbeziehung einiger der schriftlichen Selbstzeugnisse): dies., Necklines. The Art of Jacques-Louis David After the Terror, New Haven/ London 1999, v. a. Chapter 1: »The Shadow of the Guillotine«, 8-47. Vgl. auch dies., The Self in Exile. David's »Portrait of Emmanuel-Joseph Sieyès«, in: Mark Ledbury (Hg.), David after David. Essays on the Later Work, New Haven/London 2007, 232 - 251; David porträtiert Sieyès im selben Sessel sitzend wie er selbst im Selbstporträt. Michael Frieds mehr auf Spekulation und Projektion als auf einer autopsiegestützten Analyse des Bildes beruhende These, es sei als Spiegelbild zum Marat zu lesen, überzeugt nicht: Michael Fried, David/Marat: The Self-Portrait of 1794, in: Ledbury 2007 (wie oben), 191 -203. Amy Freunds Überlegungen zum changing self in der Revolutionszeit und zum Konzept von selfhood bei David fallen recht pauschal aus, eine präzise Analyse der Selbstporträts Davids oder seiner Zeitgenossen sucht man in ihrer Monographie vergeblich: Amy Freund, Portraiture and Politics in Revolutionary France, University Park 2014.

36 Vgl. Bordes 2005 (wie Anm. 14), Chapter »Art after Politics«, 1 - 17; Walczak 2015 (wie Anm. 32), IX-XV und »Epilog«, 329-347. 
37 Jacques-Louis David 1989 (wie Anm. 5), Kat.-Nr. 136, 306f., obwohl sein Schüler Delafontaine von zwei "paysages « spricht: »Au bout d'un mois environ, il fut conduit au Luxembourg. Là il fit sur toile, de sa fenêtre, deux paysages, la première esquisse des Sabines, ainsi qu'un croquis d'Homère demandant l'aumône." Wildenstein 1973 (wie Anm. 22), Nr. 1131, 114; vgl. auch ebenda, Nr. 1138, 115; vgl. Antoine Schnapper, David, témoin de son temps, Paris 1980, 169f. Zum zeichnerischen Entwurf des Homère récitant ses vers aux Grecs, der zu einem großen Historienbild ausgeführt werden sollte, vgl. Jacques-Louis David 1989 (wie Anm. 5), Kat.-Nr. 139, 310f. Der blinde, des Mitleids seiner concitoyens bedürftige Homer scheint ebenfalls eine Art Selbstvergewisserung darzustellen, der Künstler Homer fungiert als alter ego für den legitimationsbedürftigen Maler David: vgl. LajerBurcharth 1989 (wie Anm. 32), 314f. Auch das »Versöhnungsbild « der Sabinerinnen, das in der Haft seine erste Konzeption erfährt, weist argumentativ in diese Richtung; vgl. neben Ewa Lajer-Burcharth, Les Sabines ou la Révolution glacée, in: Michel 1993 (wie Anm. 1), 471-491, auch Germer/Kohle 1986 (wie Anm. 20); Tony Halliday, The Trouble with Tatius, in: The Oxford Art Journal 29, 2006, 199-211.

38 So auch der Direktor des Musée des monuments français, Alexandre Lenoir, gleich zu Beginn seines panegyrischen Textes von 1835 (wie Anm. 7), 1: „C'est dans l'atelier du peintre, le crayon et la palette à la main, que nous examinons la conduite de David, et non pas à la tribune de la Convention nationale, où, peut-être, il n'aurait jamais dû monter.«

39 Wildenstein 1973 (wie Anm. 22), Nr. 1149, 117.

40 Ebenda, Nr. 1141, 115.

41 Ebenda, Nr. 1198, 132.

42 Vgl. Alexis Joachimides, Der Blick in den Spiegel. Konventionsbrüche im Selbstbildnis am Ende des 18. Jahrhunderts, in: Margit Kern, Thomas Kirchner und Hubertus Kohle (Hg.), Geschichte und Ästhetik. Festschrift für Werner Busch zum 60. Geburtstag, München 2004, 219-232.

43 Wildenstein 1973 (wie Anm. 22), Nr. 1142, 115.

44 Ebenda, Nr. 1143, 116.

45 Vgl. David in seinem Schreiben an das Comité de sûreté générale vom 15.9.1794: "Je cherche vainement dans mon esprit et dans ma mémoire les causes du traitement que j'éprouve; il m'est impossible de les découvrir et dans la paix de ma conscience je ne peux que m'affliger de me voir l'objet d'une rigueur qui semblerait ne point s'accorder avec la justice. [...] Le jour n'est pas plus pur que le fond de mon cœur«; Wildenstein 1973 (wie Anm. 22), Nr. 1138, 114; vgl. auch ebenda, Nr. 1146, 117: »ma conscience est pure«.

46 Hierzu Richard Wrigley, The Politics of Appearances. Representations of Dress in Revolutionary France, Oxford/New York 2002.
47 Laut Lajer-Burcharth 1999 (wie Anm. 35), 43, avancierte der im Spätmittelalter von Mönchen getragene Kapuzenmantel der houppelande im Jahr II zum präferierten Kleidungsstück der Jakobiner, ein Modetrend, der vor allem von Marat gesetzt wurde; vgl. Clark 1994 (wie Anm. 35), 291 - 293.

48 Wildenstein 1973 (wie Anm. 22), Nr. 1190, 123.

49 Vgl. Clark 1994 (wie Anm. 35), 288.

50 Der von David selbst in die Welt gesetzten Behauptung, er sei ein schlechter Redner, widersprechen seine Reden vor dem Nationalkonvent und seine Verteidigungsschriften, die in ihrem rhetorischen Schliff den robespierreschen Redefeuerwerken in nichts nachstehen. Vgl. Wildenstein 1973 (wie Anm. 22), Nr. 1198, 128: »On sait que je n'ai pas le talent de la parole, et que ce moyen est le seul par lequel on puisse exercer quelque empire sur les assemblées nombreuses. On sait aussi que cette influence étoit réservée à un très petit nombre de membres de la Convention, qui dirigeoient la société, et que je n'y parloit jamais en public."

51 Warren Roberts hat Davids Selbstporträt »a visual record of his depoliticization" genannt. Warren Roberts, Jacques-Louis David, Revolutionary Artist. Art, Politics and the French Revolution, Chapel Hill/ London 1989, 101.

52 Lajer-Burcharth 1999 (wie Anm. 35), 39, spricht von "a sea of the unformed".

53 In vergleichbarer Weise schreibt T. J. Clark über die leere obere Hälfte des Marat-Bildes: »something more like a representation of painting, of painting as pure activity. Painting as material, therefore. Aimless. Ultimately detached from any one representational task. [...] a place where representation can efface itself [...] «; Clark 1994 (wie Anm. 1), 48, 51.

54 Nach 1800 wurde dann erneut ein jährlicher Wettbewerb an der wiedergegründeten Académie mit têtes d'expression eingeführt; vgl. Dorothy Johnson, Jacques-Louis David. Art in Metamorphosis, Princeton, NJ 1993, 148f. David selbst hat sich erst viel später wieder, um 1816/1821, im Exil, den têtes d'expression als künstlerischer Aufgabe zugewandt, vgl. Bordes 2005 (wie Anm. 14), Chapter "Late Drawings: Experiments in Expression «, 263-291. Zum Thema vgl. insbesondere Thomas Kirchner, L'expression des passions. Ausdruck als Darstellungsproblem in der französischen Kunst und Kunsttheorie des 17. und 18. Jahrhunderts, Mainz 1991.

55 Vgl. Johnson 1993 (wie Anm. 54), 147f.

56 Vgl. in Anlehnung an das berühmte Diktum von Louis-Antoine de Saint-Just: Lajer-Burcharth 1993 (wie Anm. 37); ähnlich erneut in: Lajer-Burcharth 1999 (wie Anm. 35), Chapter 3: »The Revolution Glacé«, 130 - 235.

57 Ebendieser Mangel an passions und Emotionalität wurde David in der frühen Kunsthistoriographie 
zum Vorwurf gemacht, die ihn als kalt und hyperrationalistisch bezeichnete. Vgl. z. B. Ernest Chesneau, Louis David, Paris 1862, 16, über die Charaktere in den Bildern Davids: »[Ils] nous laissent indifférents. Quelles passions soulèvent-ils? aucune, parce que la passion n'agita pas chez eux un seul de ses orages, et jamais dérangea un seul trait de leur physionomie«, oder: "Tout est tendu, le corps et l'esprit, l'attitude et le geste [...] la passion, qui devrait animer ces héros, les paralyse« (ebenda, 11). Vgl. zum David-Bild in der Kunsthistoriographie des 19. Jahrhunderts: Neil McWilliam, Life and Afterlife: Jacques-Louis David, Nineteenth-Century Criticism and the Construction of the Biographical Subject, in: Michael R. Orwicz (Hg.), Art Criticism and its Institutions in Nineteenth-Century France, Manchester 1994, 43-62.

58 Zur Ausschmückung der Schilderungen des ihm widerfahrenen Unrechts bedient David sich eines der klassischen antiken Künstlertopoi: des von seinen Kollegen verratenen und von der Öffentlichkeit verkannten Künstlers, der Calumnia des Apelles; vgl. Wildenstein 1973 (wie Anm. 22), Nr. 1149, 117.

59 »Depuis cette époque, qui a dessillé mes yeux, j'ai mis dans ma conduite une réserve et une circonspection poussées jusqu'à la timidité. Instruit par une funeste expérience à me défier des apparences du patriotisme, de la franchise et de la bonne foi, j'ai rompu toute liaison avec les hommes que je fréquentais avant ma détention. Je me suis tenu enfermé chez moi $[. .$.$] , je n'ai reçu ni vu personne [. .$.$] «; ebenda,$ Nr. 1198, 124.

60 Ebenda, Nr. 1198, 124; 131; vgl. auch ebenda: "l'ouvrage de la haine et des plus aveugles passions [...] les recherches laborieuses des plus furieuses passions $[\ldots]$...

$61 \mathrm{Vgl}$. das ästhetische Bekenntnis Davids in seinem autobiographischen Fragment von 1808: »Je m'explique: on est forcé quand pour vouloir trop exprimer on abandonne la marche de la nature«; ebenda, Nr. 1368, 158.

62 Vgl. z. B. seine lange Antwort vom Mai 1795 auf die Anschuldigungen, die die Commission des douze der Museumssektion an der barre des Nationalkonvents gegen ihn vorgetragen hatte: Die »révolution« sei eine jetzt vergangene Epoche »où tant de passions funestes ont presque déshonoré la nature humaine [...] un tems enfin où l'erreur usurpant l'empire de la vérité, offre aux passions déchaînées l'affreux plaisir de sacrifier l'innocence [...]«; ebenda, Nr. 1198, 127. Die geschwollene Backe wäre dann eventuell als sarkastischer Hinweis darauf zu lesen, wie unproduktiv ein der mangelnden Zügelung der passions geschuldetes, exzessives Aus-Sich-Selbst-Herausdrängen sein kann und wie selbstzerstörerisch ein öffentliches Schuldeingeständnis wäre. Vgl. auch ebenda, Nr. 1190, 123f.: "mon premier soin a été de me dépouiller, et de ma qualité de représentant et des avantages de ma position, pour n'écouter que les sentiments de la fraternité, et désarmer, s'il eût été possible, les passions envenimées que la révolution a excitées contre moi«; ebenda, Nr. 1198, 124: „Dans le cours de la Révolution, plusieurs de mes collègues [...] ont corrompu la source pure du véritable patriotisme par le mélange odieux des passions, puisque, sous prétexte de servir la liberté, ils se sont rendus coupables des plus criminels excès«.

63 Philippe Bordes interpretiert dieses Porträt überzeugend als einen Prototyp eines »distinct sansculotte realism«. Philippe Bordes, Destruction, Conservation and Creation During the French Revolution: A Matter of Style, in: Luis Arcienega (Hg.), Memoria y significado: uso y recepción de los vestigios del pasado, Valencia 2013, $107-124$, hier 121. Vgl. Philippe Bordes und Alain Chevalier, Catalogue des peintures et dessins. Musée de la Révolution française, Vizille 1996, Kat.-Nr. 16, 86-89.

64 Vgl. Plan d'éducation nationale de Michel Lepelletier, présenté à la Convention par Maximilien Robespierre, au nom de la Commission d'instruction publique, imprimé par ordre de la Convention Nationale, in: Archives parlementaires, Série I, vol. 68, 1969, 661-675, hier 666: »Régler sa vie, se plier au joug d'une exacte discipline, sont encore deux habitudes importantes au bonheur de l'être social. Elles ne peuvent se prendre que dans l'enfance; acquises à cet âge, elles deviennent une seconde nature. On calculerait difficilement à quel point une vie réglée et bien ordonnée multiplie l'existence, moralise les actions de l'homme, fait entrer dans sa conduite ce qui est bien, et la remplit tellement d'actes utiles, qu'il n'y reste plus de place, si je puis parler ainsi, pour tout ce qui est vice ou désordre«; oder 667: "Dans l'institution publique au contraire, la totalité de l'existence de l'enfant nous appartient; la matière, si je peux m'exprimer ainsi, ne sort jamais du moule; aucun objet extérieur ne vient déformer la modification que vous lui donnez.« Vgl. Tauber 2009 (wie Anm. 13), 236-242.

65 Vgl. Satish Padiyar, Chains. David, Canova, and the Fall of the Public Hero in Postrevolutionary France, University Park 2007, 17f.

66 Lynn Hunt hat darauf hingewiesen, dass die fraternité nach dem Sturz Robespierres aus der offiziellen revolutionären Bild- und Emblemsprache verschwand, da sie untrennbar mit der radikalen Phase der Terreur verbunden war (Hunt 1992 [wie Anm. 14], 13); vgl. auch zur >Symbolpolitikı der Französischen Revolution: dies., Politics, Culture, and Class in the French Revolution, Berkeley/Los Angeles 1984 (dt. Ausgabe: Symbole der Macht, Macht der Symbole. Die Französische Revolution und der Entwurf einer politischen Kultur, Frankfurt a. M. 1989). 
67 Wildenstein 1973 (wie Anm. 22), Nr. 1198, 132.

68 Abgedruckt in Bordes 1983 (wie Anm. 10), Document 19, $174-175$.

69 Wildenstein 1973 (wie Anm. 22), Nr. 1368, 155 - 158; dort unpräzise "vers 1800 « datiert, zur Datierung nach 1808 vgl. Philippe Bordes, David, Paris 1988, 10, 105.

70 Wildenstein 1973 (wie Anm. 22), Nr. 1368, 155.

71 Bordes 1983 (wie Anm. 10), 175.

72 Das spätere autobiographische Fragment geht kommentarlos von der dritten in die erste Person über.

73 Vgl. Thomas Crow, Emulation. Making Artists for Revolutionary France, New Haven 1995. Revised Edition unter dem Titel: Emulation. David, Drouais, and Girodet in the Art of Revolutionary France, New Haven/London 2012. Frz. Ausgabe: L'atelier de David. Émulation et Révolution, Paris 1995. Vgl. auch France Nerlich, Ateliers privés. Enjeux et problématiques pour l'histoire de l'art du XIX ${ }^{\mathrm{e}}$ siècle, in: dies. und Alain Bonnet (Hg.), Apprendre à peindre. Les ateliers privés à Paris 1780-1863, Tours 2013, 17 - 54; Nina Struckmeyer, Dans l'atelier des élèves de Jacques-Louis David, in: Nerlich und Bonnet 2013 (wie oben), 123 - 137.

74 Vgl. Wildenstein 1973 (wie Anm. 22), Nr. 1142, 115: "mes élèves sont sans guide«; vgl. auch Lenoir 1835 (wie Anm. 7), 2: »il fut emprisonné. [...] Cependant les élèves de David, animés d'un religieux amour pour leur maître, le réclamèrent et la Convention le leur rendit...«.

75 Wildenstein 1973 (wie Anm. 22), Nr. 1131, 114; Hervorhebung durch Kursivierung durch die Autorin; vgl. Walczak 2015 (wie Anm. 32), 227f. und 418. Bezeichnenderweise erwirkte David dann am 14. Februar 1796 beim Directoire die Entlassung seiner Schüler aus der Armee; vgl. ebenda, 452, Anm. 136.

76 Vgl. Crow 1995 (wie Anm. 73); Whitney Davis, The Renunciation of Reaction in Girodet's Sleep of Endymion, in: Norman Bryson, Michael Ann Holly und Keith Moxey (Hg.), Visual Culture: Images and Interpretations, Middletown, CT 1994, 168 -201; U1rich Pfisterer, Lysippus und seine Freunde. Liebesgaben und Gedächtnis im Rom der Renaissance oder: Das erste Jahrhundert der Medaille, Berlin 2008, v. a. $15 f$.

77 Ein ausländischer Beobachter, John Carr, konstatiert hingegen diesen Korpsgeist gerade in der DavidSchule: "David is not without his adherents. He has many pupils [...]. They are said to be much attached to him, and have formed themselves into a military corps, for the purpose of doing honor to him, and were lately on the point of resenting an insult that had been offered to his person [...] «. John Carr, The Stranger in France, or A Tour from Devonshire to Paris, London 1807 [ ${ }^{1} 1803$ ], 147f.; vgl. Bordes 2005 (wie Anm. 14), 9.
78 Wildenstein 1973 (wie Anm. 22), Nr. 1154, 118; vgl. auch ebenda, Nr. 1138, 114: »le petit nombre d'amis que l'adversité ne m'a pas ôtés, dont la plupart sont mes élèves «.

79 Vgl. die Inschrift von fremder Hand auf der Rückseite des Bildes: »Jacques Louis David né à Paris le 5 ... 1748 Peint par lui-même en mai 1791/dans son atelier dit des Horaces. Ce portrait a été donné par David à F. Gérard son Eleve, en 1809 en échange de celui de Canova, sculpteur romain/que F. Gérard venait de faire et d'offrir à son maître. Ensuite acquis à la vente de Gérard le 27 avril 1837 par Delafontaine, ancien élève de David/lequel avait [...] remporté un Prix comme Peintre d'histoire en 1798, Succéda en 1804 à son père comme ... acheté le 6 février 1861/ par le petit fils du peintre Jules David à la vente de M. Delafontaine«. Zu diesem heute in den Uffizien befindlichen Selbstporträt vgl. Jacques-Louis David 1989 (wie Anm. 5), Kat.-Nr. 98 (dort auch die Inschrift); Joachimides 2004 (wie Anm. 42); wenig ergiebig: Joanna Crown Stein, The Image of the Artist in France: Artists' Portraits and Self-Portraits Around 1800, Los Angeles 1993, 78 - 80.

80 Hierzu Sébastien Allard und Marie-Claude Chaudonneret, Le suicide de Gros. Les peintres de l'Empire et la génération romantique, Paris 2010.

81 Hierzu Walczak 2015 (wie Anm. 32), 342f.; Bordes 2005 (wie Anm. 14), $30 f$.

82 Hierzu Philippe Bordes und Alain Jouffroy, Guillotine et peinture: Topino-Lebrun et ses amis, Paris 1977; Walczak 2015 (wie Anm. 32), 344f.; Philippe Bordes, Les arts après la Terreur: TopinoLebrun, Hennequin et la peinture politique sous le directoire, in: Revue du Louvre 29, 1979, 199-212. Vgl. auch Tony Halliday, Facing the Public. Portraiture in the Aftermath of the French Revolution, Manchester/New York 1999.

83 Hierzu Crow 1995 (wie Anm. 73), passim; Walczak 2015 (wie Anm. 32), 335 - 347; James H. Rubin, New Documents on the Méditateurs: Baron Gérard, Mantegna and French Romanticism circa 1800, in: Burlington Magazine CXVII, 1975, 785 -790; George Levitine, The Dawn of Bohemianism. The Barbu Rebellion and Primitivism in Neoclassical France, University Park/London 1978. Vgl. Delécluze 1855 (wie Anm. 31), 69- 85 und die beiden Texte, die er im Anhang, 419-447, publiziert hat: Der erste, Les Barbus d'à présent et les barbus de 1800 , stammt von ihm selbst und wurde $1832 \mathrm{im}$ Livre des Cent-et-un, Bd. 7, 61 - 86 veröffentlicht; den zweiten, Les Barbus, hatte Charles Nodier am 5. Oktober 1832 in der Zeitschrift Le temps publiziert.

84 Vgl. Hunt 1992 (wie Anm. 14), 28: »The effacement of the father can also be found in what the leading revolutionary politicians said about their childhoods. Fathers had no prominence, whereas maternal in- 
fluence occupied a large place." David eliminiert in seinem Dankesbrief vom 26. Brumaire (16. November) 1794 an Boissy d'Anglas nicht nur den Vater aus dem Familienstammbaum, sondern auch seine leibliche Mutter, indem er sich als würdigen Sohn der Mutter »Malerei« bezeichnet: »La peinture ne rougira pas de me compter au nombre de ses enfants et le choix de mes sujets prouvera aux artistes qui viendront après moi combien j'ai l'âme sensible. Je n'ai jamais cherché autre chose dans mes ouvrages que d'inspirer l'amour des vertus; jamais je n'ai aimé à représenter sur la toile des scènes de fureur ou de trahison et de vengeance. Les seules passions sublimes de l'âme ont eu des attraits pour moi«; Wildenstein 1973 (wie Anm. 22), Nr. 1145, 116.

85 Ebenda, Nr. 1386, 156; vgl. 157: »les mauvaises formes françaises «; zur Rokokokritik Davids vgl. Satish Padiyar, Out of Time: Fragonard, with David, in: Melissa Lee Hyde und Katie Scott (Hg.), Rococo Echo. Art, Theory and Historiography from Cochin to Coppola, Oxford 2015, 213-231.

86 Wildenstein 1973 (wie Anm. 22), Nr. 1386, 156.

87 David spricht in seinem autobiographischen Fragment vom Frühjahr 1793 davon, dass er sich erst durch immense Anstrengung von diesem schlechten Einfluss habe befreien können: "Quand David partit pour l'Italie après avoir gagné le premier prix de l'Académie en 1774, ses ouvrages tenaient entièrement du mauvais goût de l'école d'alors et ce ne fut qu'à force de réflexion et d'étude qu'il parvint à détruire la mauvaise impression de cette première éducation«; Bordes 1983 (wie Anm. 10), 174.

88 Wildenstein 1973 (wie Anm. 22), Nr. 1386, 157.

$89 \mathrm{Vgl}$. Thomas Crow, The Abandoned Hero. The Decline of State Authority in the Direction of French Painting as Seen in the Career of One Exemplary Theme, 1777 -89, in: Ann Bermingham und John Brewer (Hg.), The Consumption of Culture, 1600 - 1800. Image, Object, Text, London/New York $1995,89-102$.

90 Wildenstein 1973 (wie Anm. 22), Nr. 1368, 157.

91 Ebenda, 158; Girodet rächt sich in einem Brief an François-Xavier Fabre vom 21. September 1811, in dem er David vorwirft, er sei nicht bereit »souffrir que d'autres élèves que les siens soient couronnés dans les concours«; zit. nach Bordes 2005 (wie Anm. 14), 70, 346, Anm. 137.

92 Bordes 1983 (wie Anm. 10), 175; vgl. Claudia Einecke (Hg.), Final Moments. Peyron, David, and "The Death of Socrates", Ohama, NE 2001; Peter J. Schneemann, Geschichte als Vorbild. Die Modelle der französischen Historienmalerei 1747-1789, Berlin 1994, 170 - 179; vgl. auch einige anregende Beobachtungen zur Rolle Platons und Xantippes im Bild in Satish Padiyars (ansonsten allerdings übertrieben stark sexualisierter) Interpretation: Who is
Socrates? Desire and Subversion in David's Death of Socrates (1787), in: Representations 102, 2008, $27-52$.

93 Vgl. Padiyar 2008 (wie Anm. 92), 27: »Socrates continues to teach, his philosophical integrity remaining undiminished even at the moment of self-annihilation."

94 In seiner anonym publizierten Lettre d'un étranger sur le Salon de 1787; vgl. Jolanta Polanowska, Lettre d'un étranger sur le salon de 1787 Stanisława Kostki Potockiego: tekst z pogranicza sztuki i polityki, in: Ikonotheka: prace Instytutu Historii Sztuki Uniwersytetu Warszawskiego 14, 2000, 237 - 246; Maria-Évelina Zóltowska, La première critique d'art écrite par un Polonais: la Lettre d'un étranger sur le salon de 1787, par Stanislas Kostka Potocki, in: Dixhuitième siècle 6, 1974, 325-341; dies., Stanislas Kostka Potocki, David, Denon et le Salon de 1787, ou la première critique d'art écrite par un polonais, in: Antemurale 24, 1980, 9-65.

95 Zit. nach Schnapper 1980 (wie Anm. 37), 83; hierzu Philippe Bordes, The Rococo in France: the Politics of a Decorative Style, in: Dietrich Erben und Christine Tauber (Hg.), Politikstile und die Sichtbarkeit des Politischen in der Frühen Neuzeit (im Druck, erscheint Passau 2016).

96 Vgl. Goethes beruhigende, Extreme ausgleichende Beschreibung der charakterlichen und affektiven Äquivalente in der Anordnung der Jünger in Leonardos Abendmahl, ein auch inhaltlich dem Sokrates-Thema verwandter Stoff: Christus kündigt beim Letzten Abendmahl an, dass ein Verräter unter ihnen sei, der durch Verrat seinen, also Christi, Tod herbeiführen werde; Johann Wolfgang Goethe, Joseph Bossi über Leonard da Vinci Abendmahl zu Mayland, in: ders., Sämtliche Werke nach Epochen seines Schaffens. Münchner Ausgabe, Bd. 11.2, hg. von Johannes John u. a., München 1994, 403 -437, v. a. $408 \mathrm{f}$.

97 Wildenstein 1973 (wie Anm. 22), Nr. 1198, 132.

98 Vgl. Timothy Wilson-Smith, Napoleon and his Artists, London 1996; Werner Telesko, Napoleon Bonaparte: der "moderne Held " und die bildende Kunst 1799-1815, Wien 1998; und die Rezension von Claudia Hattendorff von beiden Titeln in: Kunstchronik 53, 2000, 46-55. Zu einer differenzierten Einschätzung des Verhältnisses Davids zu Napoleon vgl. Bordes 2005 (wie Anm. 14), Chapter: »In the Service of Napoleon«, 19 - 123.

99 Hierzu Padiyar 2007 (wie Anm. 65), v. a. Chapter 1: »Heroism After the French Revolution: David's Leonidas at Thermopylae«, 9-50 und Chapter 5: "Sade/David, in Chains«, 142 - 174; Bordes 2005 (wie Anm. 14), 196 -204; Michael Rohlmann, Bonaparte versus Leonidas. Zur Psychomachie der Bilder bei Jacques-Louis David, in: Wallraf-Richartz-Jahrbuch 
75, 2014, 267 - 284; Godehard Janzing, »Leonidas« at the Crossroads: The Crux of the Composition, in: Ledbury 2007 (wie Anm. 35), 72 - 89; Thomas W. Gaehtgens, Jacques-Louis David: Leonidas bei den Thermopylen, in: Herbert Beck, Peter C. Bol und Eva Maeck-Gérard (Hg.), Ideal und Wirklichkeit der bildenden Kunst im späten 18. Jahrhundert, Berlin 1984, 211 -251; Miriam R. Levin, La définition du caractère républicain dans l'art français après la Révolution. Le Léonidas aux Thermopyles de David, in: Revue de l'Institut Napoléon 137, 1981, 40 - 67. Eine wichtige Quelle zum Bildverständnis stellt Davids zwölfseitige Selbstbeschreibung des Bildes dar: Explication du tableau des Thermopyles, de M. David, Paris 1814. Diesem Selbstzeugnis ist selbstverständlich mit der gebührenden quellenkritischen Distanz gegenüber jeder Künstler-Selbstaussage zu begegnen.

100 David selbst bezeichnete es in einem Brief vom 21. November 1814 als "mon meilleur ouvrage«; Wildenstein 1973 (wie Anm. 22), Nr. 1703, 196.

101 Zur Gleichsetzung der Spartaner an den Thermopylen mit den jakobinischen Idealen in der zweiten Hälfte der 1790er-Jahre vgl. James H. Rubin, Painting and Politics, II: J.-L. David's Patriotism, or the Conspiracy of Gracchus Babeuf and the Legacy of Topino-Lebrun, in: Art Bulletin 58, 1976, H. 4, $547-568$, hier 567: »The sacrifice of Leonidas exemplified a kind of patriotism that now seemed outdated - a completely conscious, perhaps fanatic willingness to face or even to seek a martyrdom in the name of a greater cause«; vgl. Elizabeth Rawson, The Spartan Tradition in European Thought, Oxford 1969, v. a. 230 - 291 (zu Rousseau und Robespierre). Vgl. auch Gregor Stemmrich, Davids »Leonidas bei den Thermopylen«. Klassizistisch vollzogene Kunstautonomie als »Patriotisme sur la toile«, in: Gudrun Gersmann und Hubertus Kohle (Hg.), Frankreich 1800. Gesellschaft, Kultur, Mentalitäten, Stuttgart 1990, 64-80, hier 64f.: »Unter politisch repressiven Bedingungen wollte David das republikanisch-patriotische Ideal der Revolution szumindest ästhetisch gewahrt sehen; Kunstautonomie gilt ihm als Minimalbestimmung eines politisch-patriotischen Ideals."

102 David 1814 (wie Anm. 99), 5.

103 Hierzu Steven A. Nash, The Compositional Evolution of David's Leonidas at Thermopylae, in: Metropolitan Museum Journal 13, 1979, 101 - 112.

104 Werner Busch, Das sentimentalische Bild. Die Krise der Kunst im 18. Jahrhundert und die Geburt der Moderne, München 1993, 137 - 180.

105 Vgl. Régis Michel, La solitude de Léonidas, in: Posséder et détruire. Stratégies sexuelles dans l'art d'Occident (Ausst.-Kat. Paris, Musée du Louvre), hg. von Régis Michel, Paris 2000, 121 - 123, hier 123:
"Léonidas lui-même, qui se tient de face, au centre de la scène, dans une frontalité rigoureuse, laquelle est, en bonne rhétorique, le registre attitré de la première personne - le registre du sujet. Léonidas dit je. Aussi n'est-il plus dans l'action, mais dans une parenthèse, qui est digressive, sinon suspensive. À la ferveur de la troupe s'oppose la hauteur du chef: à la suractivité des figurants, la discursivité du héros."

106 Ebenda, 122: "remake des Horaces en version soft, trente ans après «.

107 David 1814 (wie Anm. 99), 6f.: »Deux jeunes gens de dix-sept à dix-huit ans, que, par intérêt pour leur âge, et à cause des liens de sang, Léonidas avait voulu éloigner du combat, sous le prétexte d'une commission secrète pour les magistrats de Lacédémone, ont pénétré l'intention de leur général; ils lui font cette réponse énergique: Nous ne sommes pas ici pour porter des ordres, mais pour combattre; et, sans attendre sa réponse, impatiens de se placer dans les rangs, l'un se hâte de rattacher son cothurne, l'autre court embrasser son vieux père qui lui fait ses derniers adieux.«

108 Padiyar 2007 (wie Anm. 65), 43f.

109 Alex Potts hat in Bezug auf den Léonidas von der representation of an exclusively masculine imaginary world « und von dem »quasi-totalitarian monism « des Bildes »in its repressive projection of an exclusive masculinity" gesprochen. Alex Potts, Flesh and the Ideal. Winckelmann and the Origins of Art History, New Haven/London 1994, 237; vgl. auch ders., Beautiful Bodies and Dying Heroes: Images of Ideal Manhood in the French Revolution, in: History Workshop Journal 30, 1990, H. 1, 1-21, URL: http://hwj.oxfordjournals.org/content/30/1/1. full.pdf (letzter Zugriff am 17. Juli 2016).

110 Auch Girodets Manier ist in Davids Darstellung in seinem autobiographischen Fragment von 1808 überzogen, unnatürlich, »trop recherché« und somit manieriert, seine »figures aussi contournées ressemblent à des monstruosités«; Wildenstein 1973 (wie Anm. 22), Nr. 1368, 158.

111 Bordes 1983 (wie Anm. 10), 174.

112 Vgl. Johnson 1993 (wie Anm. 54), 140 - 145.

113 Diesen »défaut de clarté, et celui de précision et d'unité d'action« tadelte schon Jean-Baptiste-Bon Boutard in seiner Kritik des Bildes im Journal des Débats vom 11.12.1814, 1f.; vgl. Gaehtgens 1984 (wie Anm. 99), 243.

114 Zur Genese dieses psychotischen Vaterbildes vgl. neben Hunt 1992 (wie Anm. 14): Duncan 1981 (wie Anm. 25). James H. Rubin hat auf die Konjunktur von Oedipus-Bildern in der nachrevolutionären französischen Malerei hingewiesen: James H. Rubin, Oedipus, Antigone and Exiles in Post-Revolutionary French Painting, in: Art Quarterly 36, 1973, $141-171$. 
115 Hierzu Stemmrich 1990 (wie Anm. 101), 80; vgl. Miriam R. Levin, David, De Staël, and Fontanes: The Leonidas at Thermopylae and some Intellectual Controversies of the Napoleonic Era, in: Gazette des Beaux-Arts 95, 1980, 5-12.

116 Vgl. Martin Kemp, J.-L. David and the Prelude to a Moral Victory for Sparta, in: Art Bulletin 51, 1969, H. 2, $178-183$, hier 183: "The message is one of moral beauty before physical power. Though Leonidas was to be defeated militarily, David wished to make it clear that the moral and spiritual victory after death was to belong to him, the virtuous martyr, not to Xerxes, the violent aggressor."

117 Vgl. Ralph Ubl, Eugène Delacroix' Figuration der Freiheit, in: Friedrich Balke, Harun Maye und Leander Scholz (Hg.), Ästhetische Regime um 1800, München 2009, 139 - 164, hier 150: In den Sabinerinnen habe David in vergleichbarer Weise »die laterale Ausrichtung auf die Betrachter geöffnet und als Reflexionsraum bestimmt«.

118 Johnson 1993 (wie Anm. 54), 151 - 162. Vgl. Claire Regius, Comtesse Lenoir-Laroche, Analyse du tableau de Léonidas aux Thermopyles, in: dies., $L a$ France, ou réflexions sur le tableau de Léonidas de M. David, adressées aux défenseurs de la patrie, par une française, Paris 1815, 13 -42, hier 23f.: »Comment bien exprimer cette vertu héroïque, cette fermeté invincible de Léonidas, ce caractère moral si difficile à peindre, puisque l'action en est toute intérieure. [...] la difficulté de ce tableau étoit sur-tout de rendre d'une manière animée des sentiments calmes; comme la vertu, et la mort pour la patrie et pour la loi? «

119 Vgl. Lenoir-Laroche 1815 (wie Anm. 118), $27 \mathrm{f}$ : "Dans cette tête sublime, toutes les expressions sont réunies, c'est le justum et tenacem, l'homme viril et plein de courage; toute la grandeur de la patrie est présente à son âme profonde; l'invocation fixe ses yeux vers le ciel dans une immobilité qui exprime toute l'étendue de son dévouement."

120 Vgl. hierzu Bordes 2005 (wie Anm. 14), 270 f.
121 Diese futurische Ausrichtung des Gemäldes konstatierte bereits Lenoir-Laroche 1815 (wie Anm. 118), 26: »Pour que la peinture, cette poésie muette, produise tout l'effet qu'on doit en attendre, il faut qu'elle laisse derrière elle beaucoup d'événemens qu'elle caractérise par la fin de l'action, ou qu'elle fasse deviner les plus grandes choses dans l'avenir; c'est l'action de l'avenir que représente le tableau des Thermopyles [...]«.

122 David 1814 (wie Anm. 99), 7f., schildert diesen Moment der zeitenüberdauernden Zukunftsstiftung im Modus der Erhabenheit: »Un autre guerrier veut, avant le combat, transmettre à la postérité le souvenir de cette terrible et glorieuse journée: il s'élance, et grave avec le pommeau de son épée, sur la roche couverte de mousses, ces mots à jamais mémorables: [...] Étranger, va dire aux Lacédémoniens que nous sommes morts ici, en obéissant à leurs ordres. Non moins passionnés pour la gloire de leur pays, quatre jeunes Spartiates, quatre amis se tenant étroitement serrés, s'embrassent pour la dernière fois, et jurent, en offrant leurs couronnes, de réaliser par une mort glorieuse l'obligation que ces mots leur imposent".

123 Vgl. Nina Athanassoglou, Under the Sign of Leonidas: The Political and Ideological Fortune of David's Leonidas at Thermopylae under the Restauration, in: Art Bulletin 63, 1981, H. 4, 633-649.

124 Padiyar 2007 (wie Anm. 65), 16; vgl. auch ebenda, 48: »The paradox of the image is that even within its conditions of postrevolutionary fragmentation of the political subject, Leonidas as such asserts the continuing possibility of a politically engaged radical art practice. In the same way, it articulates both the possibility of community-to-come, and, in its very sincoherencer, the historic conditions of its fragmentation."

125 Hierzu Bordes 2005 (wie Anm. 14), 53.

126 Von den vier Großaufträgen für Zeremonialbilder zur Kaiserkrönung im Jahr 1804 wurden allerdings nur der Sacre (1808) und die Distribution des aigles (1810) ausgeführt.

Abbildungsnachweis: 1 Ausst.-Kat. Jacques-Louis David 1989 (wie Anm. 5), 293, Kat.-Nr. 124. - 2 Kersaint 2010 (wie Anm. 9), 217, Abb. 21. - 3 Kersaint 2010 (wie Anm. 9), 230, Abb. 25. - 4 Schnapper 1980 (wie Anm. 37), 145, fig. 84. - 5 Ausst.-Kat. Jacques-Louis David 1989 (wie Anm. 5), 163, Kat.-Nr. 67. - 6 Ausst.Kat. Jacques-Louis David 1989 (wie Anm. 5), 195, Kat.-Nr. 85. - 7 Ausst.-Kat. Jacques-Louis David 1989 (wie Anm. 5), 305, Kat.-Nr. 135. - 8 Bordes und Chevalier 1996 (wie Anm. 63), 87, Kat.-Nr. 16. - 9 Lajer-Burcharth 1999 (wie Anm. 35), plate 5. - 10 Padiyar 2007 (wie Anm. 65), 12, fig. 2. - 11 Padiyar 2007 (wie Anm. 65), 44, fig. 14. - 12 Ausst.-Kat. Jacques-Louis David 1989 (wie Anm. 5), 501, Kat.-Nr. 216. - 13 Wildenstein 1973 (wie Anm. 22), Frontispiz. 